\title{
Review Article \\ Electronic Nose Based on Nanomaterials: Issues, Challenges, and Prospects
}

\author{
Niranjan S. Ramgir \\ Thin Film Devices Section, Technical Physics Division, Bhabha Atomic Research Center, Mumbai 400 085, India \\ Correspondence should be addressed to Niranjan S. Ramgir; niranjanpr@yahoo.com
}

Received 25 August 2013; Accepted 16 September 2013

Academic Editors: W. Bao and J. Li

Copyright (C) 2013 Niranjan S. Ramgir. This is an open access article distributed under the Creative Commons Attribution License, which permits unrestricted use, distribution, and reproduction in any medium, provided the original work is properly cited.

\begin{abstract}
The ability to precisely control the morphology and dimension coupled with the tunable surface reactivity has led to the widespread investigation of nanomaterials for various device applications. The associated high surface area to volume ratio implies that large numbers of atom are residing on the surface and are available for interaction. Accordingly, nanomaterials have demonstrated the potential to realize sensors with ultrahigh sensitivities and fast response kinetics. The smaller size further provides the possibility of miniaturization and integration of large number of devices. All these properties makes them an attractive candidate for the fabrication of electronic nose or e-nose. E-nose is an intelligent chemical-array sensor system that mimics the mammalian olfactory system. The present paper critically reviews the recent development in the field of nanomaterials based e-nose devices. In particular, this paper is focused on the description of nanomaterials for e-nose application, specifically on the promising approaches that are going to contribute towards the further development of this field. Various issues related to successful utilization of different nanomaterials for commercial application are discussed, taking help from the literature. The review concludes by briefing the important steps taken towards the commercialization and highlighting the loopholes that are still to be addressed.
\end{abstract}

\section{Introduction}

The term "electronic nose" was coined in 1988 by Gardner and Bartlett wherein they defined e-nose (EN) as "an instrument which comprises an array of electronic chemical sensors with partial specificity and appropriate pattern recognition system, capable of recognizing simple, or complex odors" $[1,2]$. It is interesting to note that not everything that can be measured with the help of EN has a smell or odor and hence sometimes the word can be misleading. More appropriately it can be defined as "an intelligent chemical-array sensor system that mimics the mammalian olfactory system" (Figure 1) [3-5]. It is important to note that EN functions are less in comparison to that of human nose applications as they are mostly developed for desired applications. That is to say that an EN nose developed for biosensor cannot be used for other applications like food quality or environmental monitoring. ENs are application specific, that is, an all purpose ideal EN is not available. EN can however be used for more applications wherein the sensor array employed needs to generate a response. For example, EN developed for chemical sensors can be used for measuring the food quality in particular alcoholic beverages and food freshness's. In both the application the sensor sees only the odor it is exposed to and accordingly, with the appropriate training period can be used to classify, identify, and sometimes quantify the odorant. As shown in Figure 1, the main components of the EN include an array of chemical sensors, electronic circuitry, and data analysis software. Additionally, it may also consist of a sampling, filtering, and conditioning system (for a reproducible collection of the mixture). It is clearly evident that the EN comprises the technical equivalent of every part of mammalian nose. Incorporation of all the components into a single device leads to the increase in the size of an EN. A comparison between natural and artificial olfactory system clearly indicates that still natural systems are the best and surpasses the advantages offered by the artificial systems [6]. However, when specific application is considered 


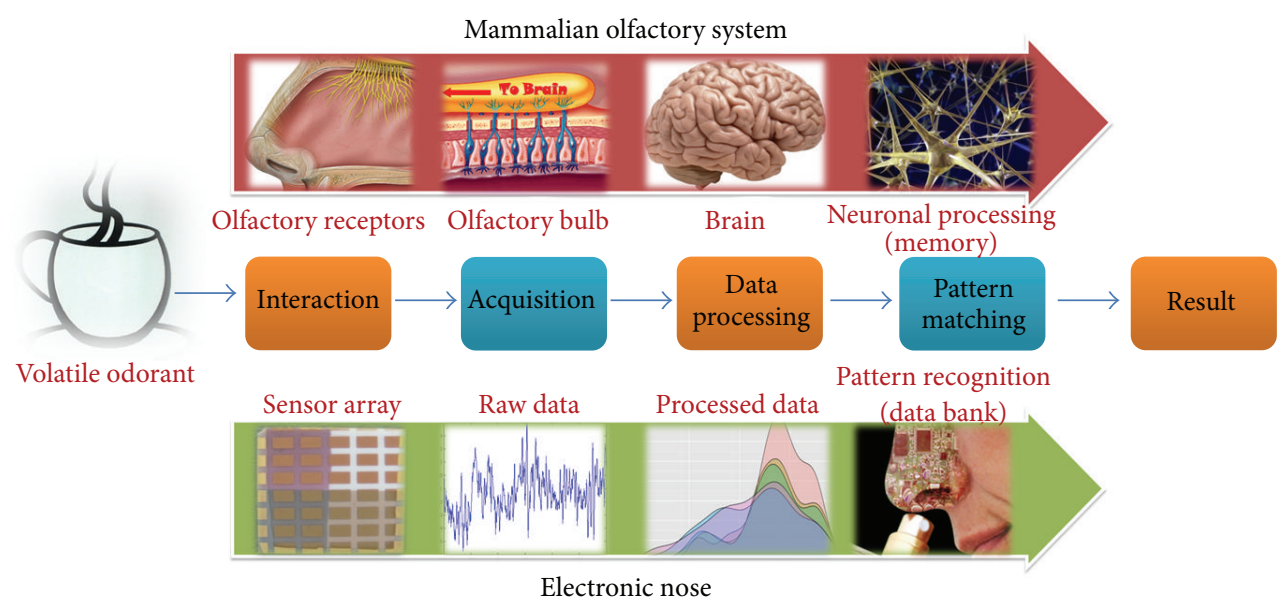

FIGURE 1: Schematic showing the comparison between mammalian olfactory system and an electronic nose.

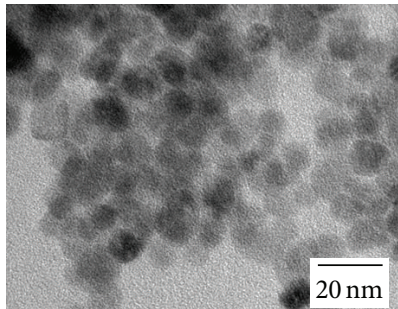

(a)

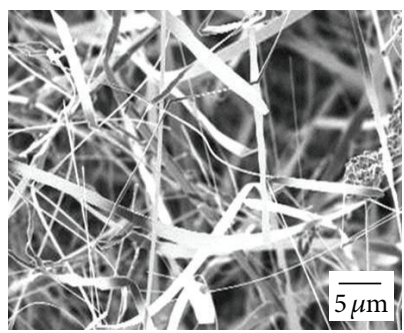

(d)

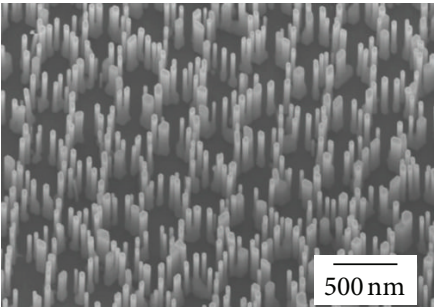

(b)

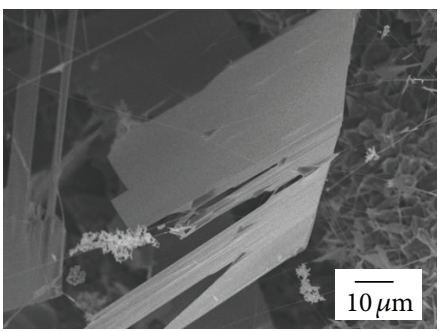

(e)

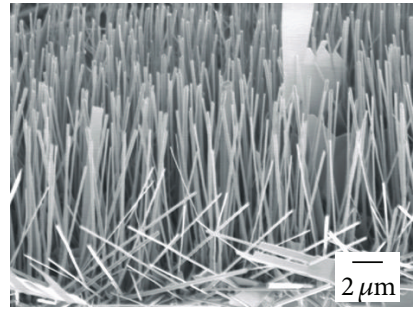

(c)

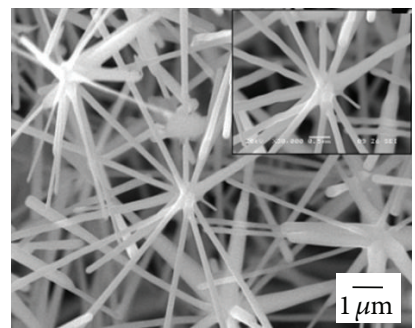

(f)

FIGURE 2: Wealth of interesting nanostructures for potential EN application (a) NPs, (b) nanorods, (c) NWs, (d) nanobelts, (e) nanosheets, and (f) multipods.

the artificial system advantageously surpasses the natural olfactory systems.

With the advent in nanoscience and nanotechnology, novel nanomaterials (both organic and inorganic) and techniques with potential use for EN applications are being developed. Figure 2 shows the wealth of interesting nanostructures that have demonstrated the potential for EN applications. The abundance of nanomaterials like nanospheres, nanocubes, nanobipyramids, nanopencils, NWs, nanotubes, nanobelts, nanorings, and nanohelixes has led to the upsurge in their synthesis and possible applications. The associated high surface area to volume ratio of the nanomaterials is particularly advantageous for the sensor application as most of the material is made available for interaction with the target analytes. Fast response time $(<\mathrm{ms})$, high sensor response values signifying better separation between the interfering responses, detection of very low concentrations, and smaller training periods are some of the advantages. However, there are reports on the developments of the EN based on nanomaterials but realizing a complete commercial device is still a daunting challenge. The present paper critically reviews the recent development in the field of nanomaterials based EN devices. In particular, this review paper is focused on the description of nanomaterials for EN application, specifically on the promising approaches that are going to contribute toward the further development of this field. Various issues related to successful utilization of different nanomaterials including $1 \mathrm{D}$ and $2 \mathrm{D}$ structures for commercial application are discussed taking help from the literature. The review concludes briefing the important steps taken towards the commercialization and highlighting the loopholes that are still to be addressed. Considering the vast research span and 


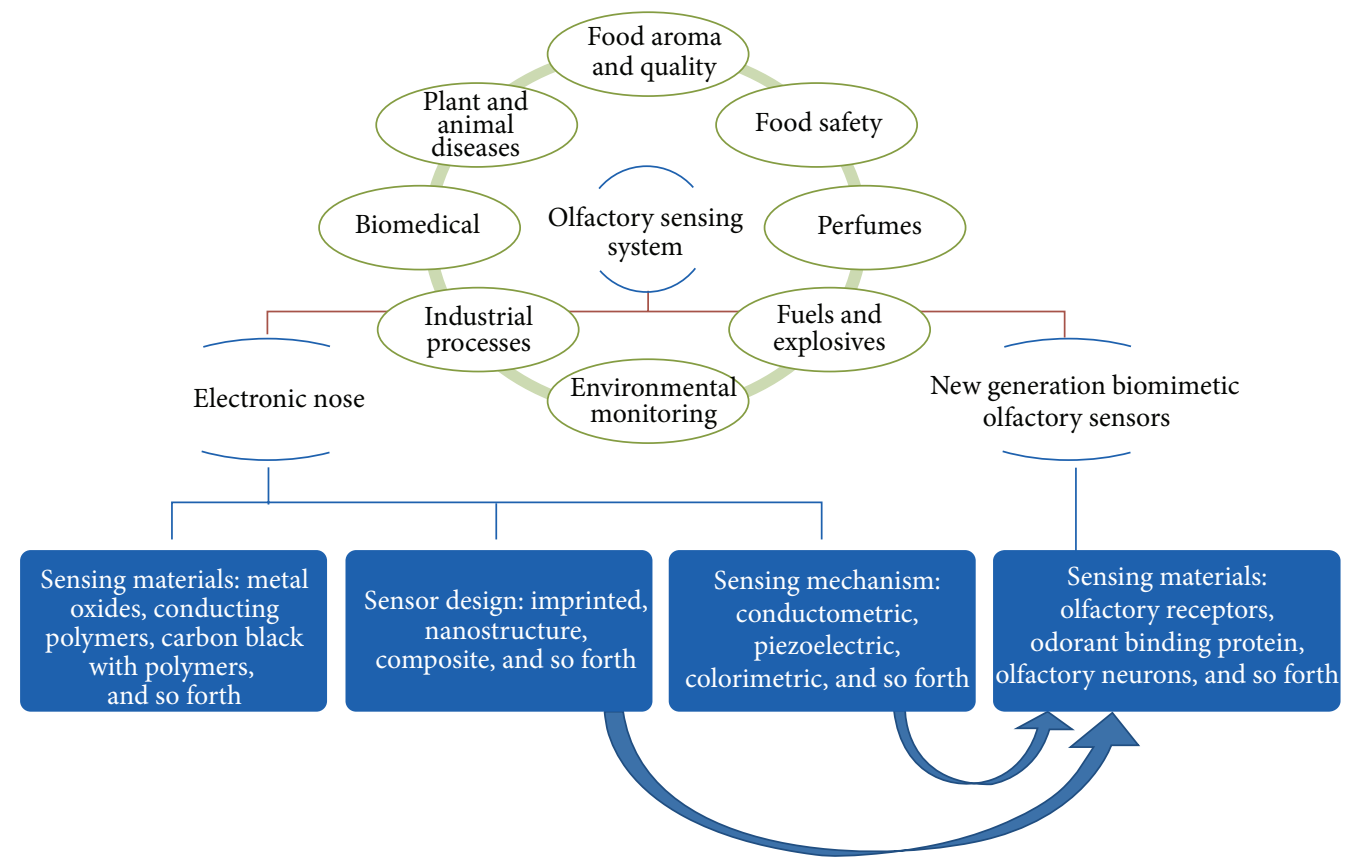

FIgure 3: Artificial olfactory sensing systems and their applications. Published with permission from Sankaran et al. [6], Copyright (c) 2012 Elsevier.

the number of papers that are being added to the literature many of the important papers are more likely to be missed; however, a proper care has been taken so as to include all the important papers that are being published prior to and in the course of this paper. I hope that the present paper will be helpful for understanding the importance and effective use of nanomaterials in realizing commercial "electronic nose" devices.

1.1. EN Applications. Figure 3 shows the field in which ENs demonstrated potential applications [6]. ENs have been successfully employed in the detection of food quality [712], waste water management [13], flammable liquids [14], and environment: air pollution [15], water pollution [16, 17], beauty and health care [18-21], medical diagnostics [22-27], and warfare [28-30]. In determination of food safety the most common use is for the determination of quality of tea [31], milk, alcoholic beverages [32-35], fruits [36, 37], meats and fishes [38-40], cheese, and other dairy products $[7,41,42]$. EN for gas sensors have been demonstrated for methane [43], ethanol, toluene, o-xylene [44], $\mathrm{CO}$, and $\mathrm{CH}_{4}$ [45]. In medical diagnostics, ENs have been demonstrated to be successful for detection of various biomolecules including cancer biomarkers [46] necessary for early diagnosis and faster treatment. One of the major advantages of artificial system over the natural EN is that the data is interpreted without any bias. Natural EN have the risk of false human sensory evaluations and poor decision making as they are dependent on the physiological and psychological status.

\section{Components of E-Nose}

Figure 4 shows a schematic of the simplified and complete EN device. It consists of three main components, namely,

(i) multiple sensor array,

(ii) data acquisition system, and

(iii) pattern recognition algorithm.

2.1. Multiple Sensor Array. Multiple sensor array (MSA) is an array of the sensing elements (sensors) which are able to transduce chemical changes or interactions into measureable signals. Chemical sensors, which are the heart of the system, can be divided into three categories according to the type of sensitive material used: inorganic crystalline materials (e.g., semiconductors, as in MOSFET structures, and metal oxides), organic materials and polymers, and biologically derived materials [47]. The sensing elements are chosen depending on the type of analyte/gas that is required to be detected. One of the requirement of MSA is that it should be a balanced combination of identical and different types of sensors. One of the important questions for fabricating an EN device is "what type of sensors should be usedidentical or different?" Identical sensors are required for the improvement in the precision, and different sensors are required for cross-verification of data. Another important question is that "how many sensors one should use?" The answer to the question lies in the information that is sought. If the background is unknown, mixtures are present, or background gases are changing in concentration, more number 


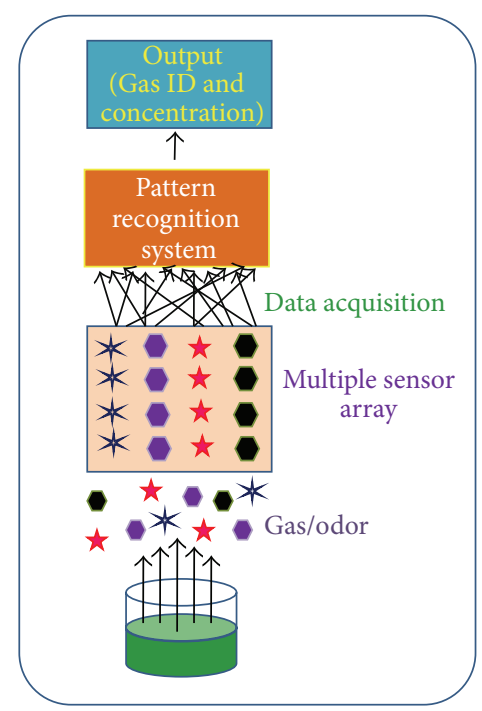

FIGURE 4: Schematic of a simplified and complete EN.

of sensorsare needed to avoid ambiguity in interpreting the output signal pattern, and accomplish optimal discrimination avoiding false alarm signatures. Additionally, EN can be trained to ignore some of the bad sensors and select sensors important for a particular task. A limited number of sensors are used only when the information sought is to distinguish between a series of pure substances maintained at known concentration.

2.2. Data Acquisition System. The data acquisition system is responsible for capturing the signals provided by the sensor array and then delivering them to the process processing or computing system that has the appropriate software for processing such information. The control and data acquisition systems can be integrated into a single device, which can be a data acquisition card, a microcontroller, a (Digital Signal Processor) DSP or a computer. Reliable connections between electrodes and measuring device are ensured for reproducible and quality data. It must also have adequate power stage to handle the elements that consume more power. The data acquisition system must be capable of handling and storing data from multiple sensors simultaneously. The group of such data is initially used for preparation of the data bank.

2.3. Pattern Recognition Algorithm. The aim of pattern recognition algorithm (PRA) is to classify, identify, and where necessary quantify the vapor or odors of concern based on the data stored in data-bank. Patterns or finger prints from known analytes are used to construct a database and train a pattern recognition system so that the unknown analytes can subsequently be classified and identified. There are various methods used to facilitate this process. The processes can be divided mainly into three groups.

2.3.1. Graphical Analysis. The simplest form of data reduction is graphical analysis useful for comparing samples or comparing aroma identification elements of unknown analytes relative to those of known sources in reference libraries. An array of sensors that individually respond to vapors can produce a distinguishable response pattern for each separate type of analyte or mixture. Each individual sensor responds to a variety of gases, but the pattern of differential responses across the array produces a unique pattern for each gas, that is, a distinct fingerprint for each type of gas [48]. The pattern of changes (optical: intensity; electrical: resistance or current magnitude) on the array is diagnostic of the vapor, while the amplitude of the patterns indicates the concentration of the vapor. There are various techniques employed for this purpose, like bar graph, polar, and offset polar plots.

2.3.2. Multivariate Data Analysis. Multivariate data analysis (MDA) comprises a set of techniques for the analysis of data sets with more than one variable by reducing high dimensionality in a multivariate problem when variables are partly correlated, so they can be displayed in two or three dimensions. MDA is based on the principle of multivariate statistics, which involves observation and analysis of more than one statistical outcome variable at a time. There are varieties of multivariate data analysis methods, like

(i) principal component analysis (PCA),

(ii) canonical discriminate analysis (CDA),

(iii) featured within (FW), and

(iv) cluster analysis (CA).

For EN data analysis, MDA is very useful when sensors have partial-coverage sensitivities to individual compounds present in the sample mixture. Multivariate analysis can be divided into untrained or trained techniques. Untrained techniques are used when a database of known samples has not been previously built, therefore, it is not necessary nor intended for recognizing the sample itself, but for making comparisons between different unknown samples to discriminating them. The simplest and most widely used untrained MDA technique is principal component analysis. PCA is most useful when no known sample is available or when hidden relationships between samples or variables are suspected. On the contrary, trained or supervised learning techniques classify unknown samples on the basis of characteristics of known samples or sets of samples with known properties that are usually maintained in a reference library that is accessed during analysis.

2.3.3. Network Analysis. Network analysis provides the crucial relationships and associations between many objects of different types that are not apparent from isolated pieces of information. There are various techniques employed for the purpose, for example,

(i) artificial neural network (ANN) and

(ii) radial basis function $(\mathrm{RBF})$.

The artificial neural network (ANN) is the best known and most evolved analysis techniques. An artificial neural network, often just called a neural network, is a mathematical 
model inspired by biological neural networks. A neural network consists of an interconnected group of artificial neurons, and it processes information using a connectionist approach to computation. In most cases a neural network is an adaptive system that changes its structure during a learning phase. Neural networks are used to model complex relationships between inputs and outputs or to find patterns in data $[49,50]$. Various instrument-training methods are employed through pattern-recognition algorithms that look for similarities and differences between identification elements of known patterns found in an analyte-specific reference library. The training process requires a discrete amount of known sample data to train the system and is very efficient in comparing unknown samples to known references. The result of ANN data analysis usually is in the form of a percentage match of identification elements in the sample with those of patterns from known sources in the reference library.

From graphical to network analysis, precision increases on the cost of increase in complexity. The choice of method utilized depends on the type of available input data acquired from the sensors and the type of information that is sought. A vast amount of research is devoted to the development of application specific and appropriate PRA and reference to them can be found in the journal "Journal of Multivariate Analysis" by Elsevier.

\section{Classification of EN}

$\mathrm{EN}$ are generally classified based on the detection principle involved or the type of sensor used. These includes the following.

3.1. Optical Sensor Systems. Herein the modulation of optical properties, namely, absorption, transmission, fluorescence, optical layer thickness, polarization, and so forth are measured [51].

3.2. Mass and Ion Mobility Spectrometry. For mass spectrometry the different components of the analytes are separated by measuring the mass to charge ratio under the application of electric and/or magnetic fields $[52,53]$. In case of ion mobility along with the reduced mass and charge, the mobility of the ions is also measured [54-56]. These techniques however suffer from the drawback of technical complexity and vaccum operation.

3.3. Gas Chromatography. The sample, transported by the mobile phase (gas), is directed over the stationary phase (liquid or solid) and interacts with it. Depending on physical and chemical properties, such as the boiling point, the polarity, H-bonding, and polarizability, the affinity of each single substance for the stationary phase is different. The partition behavior determines the retention time of the components and, consequently, the order of elution [57].

3.4. Infrared Spectrometry. The characteristic absorption bands give information regarding the type of chemical bonds.
And hence can be employed for the determination of single or multiple chemicals through unique fingerprint spectrum and using appropriate pattern recognition algorithm $[58,59]$.

3.5. Chemical Sensors. These work on the principle of change in the properties (electrical, mechanical, optical, and piezoelectric) of the sensing material as a result of chemical interaction with the test gas or analyte. The ENs based on this principle are highly popular and widely used due to their simple operation, ability to control and tailor the different process parameters, and close resemblance to the mammalian olfaction. These are often divided into the metal oxide sensors [60], metal oxide field effect transistor, surface and bulk acoustic wave, and conducting polymers [61]. Chemiresistive/FET-based sensors are highly exploited due to the low cost, low power consumption, miniaturization, and multiplexing capabilities [62].

As mentioned above various techniques and materials have demonstrated their applicability for the possible EN applications. However, EN based on nanomaterials is looked upon as a next generation technique fulfilling almost all the requirements of future technologies and commercial health and beauty product [63]. These include ease of synthesis, miniaturization, control over dimensions, and tunable surface reactivity.

\section{Why Nanomaterials?}

The ability to precisely control the dimensions of both organic and inorganic nanomaterials has led to an upsurge in the field of their synthesis [64-66]. The associated high surface area to volume ratio and the finite or quantum size effects have led to many new interesting phenomenon's in physics, chemistry, biology, and materials science [67]. This has lead to a new field of "Nanoscience and Nanotechnology." Of the various applications being investigated, nanomaterials have emerged as a general platform for the direct electrical detection of biological and chemical species with enhanced sensing characteristics [68-72].

One of the most attractive classes of materials for functional nanodevices is semiconductors or in particular metal oxides $[73,74]$. They offer the advantages of simple operation and ease of fabrication, simple precursors and the potential for compatibility with microelectronic processing, low cost, and low power consumption. Sensors are characterized by the three basic factors, namely, receptor, transducer, and utility [75]. The receptor function takes account of the interaction of target molecules with the sensor surface while the transducer function basically transforms the interaction into a measurable response (usually electrical). The third factor, utility, determines the effective utilization of surface and bulk grains for the measured response. The transducer function is deeply correlated to the microstructure of the elements, that is, the grain size $(D)$ and the depth of the surface space-charge layer $(L)$. The sensors response is drastically enhanced when grain size $D$ is $\leq 2 L$. Another way to tailor the response is by means of controlling $L$ which can be achieved by introducing defect states or midgap states by means of doping or surface 
modification [76]. It has been demonstrated that reduction in the grain size close to the Debye length or mean free path of an electron results in the exponential increase in the sensor response [77, 78]. In order to improve the sensing response efforts have been directed primarily to realize smaller and smaller structures that can be effectively utilized for achieving sensors with improved response characteristics or the socalled "next generation sensors." The enhanced response in these cases is attributed to the high surface area to volume ratio enabling high surface reactivity. Accordingly, various nanomaterials are being synthesized and investigated for possible sensing applications. The basic nanoforms include nanoparticles, nanowires (NWs), nanotubes, and nanobelts [79]. Along with this different 3D heterostructures like nanomultipods, nanorings, nanohelixes, nanoflowers, and so forth are also being investigated in great detail [80-87]. Nanomaterials offer various advantages that includes

(i) high surface area to volume ratio;

(ii) enhanced and tunable surface reactivity;

(iii) faster response kinetics;

(iv) size and effective Debye length comparable to the size of analytes;

(v) crystalline dislocation-defect free structure with precise chemical composition, surface, and terminations;

(vi) high crystallinity implies superior stability;

(vii) ease of incorporation into microelectronic devices;

(viii) possibility of high integration densities and;

(ix) smaller size implies low power consumption;

(x) and low cost.

Of the different forms nanoparticles, NWs, and nanotubes (NTs) have been investigated in detail. Although, nanoparticles-based sensors exhibited superior sensing properties; however, they suffer from the drawback of poor structural stability or degradation due to grain coalescence when operated for longer time or at high operating temperatures [88]. Incorporation of microadditives has been demonstrated to improve the thermal stability and decrease the effective grain size [89]. Presence of additives (5-10\%) over the sensor surface significantly reduces the surface diffusion inhibiting the grain growth [90]. Introduction of high concentrations of additives could drastically change the material property affecting adversely the sensing properties. Higher loading implies large number of structural defects implying pinning of the surface Fermi level and limitation on the Fermi level shift [91]. A room temperature sensor based on nanoparticles have also been reported, but a strong dependence on humidity is observed for these sensors, which is also a major concern [92].

One dimensional (1D) structures, namely, NTs and NWs with associated high aspect ratio, that is, length to diameter ratio of 20 or larger, are promising for sensing applications. Their use as a sensing material should reduce instabilities and drift in electrical properties. A high degree of crystallinity and atomic sharp terminations make them very promising for better understanding of sensing principles and for the development of a new generation gas sensor [93-96]. The main advantages of 1-D nanomaterial-based sensors are enhanced sensitivity, spatial resolution, temporal stability, and rapid response associated with individual structures crucial from device point of view [97]. Accordingly, NWs and NTs are looked upon as a potential candidate for realizing next generation sensors. Compared to other nanomorphologies, NWs offer the advantages of relatively simple preparation methods allowing large-scale production, ease of fabrication, and manipulation. As a gas sensing material both NWs and NTs provide the advantages of tunable surface reactivity by means of controlling the aspect ratio and tailored loading of target specific receptor species or catalyst. Their length serve as resistance free pathway for electron transfer thereby improving the reaction kinetics, that is, response and recovery time. The longer length provides a mean to measure the response using a four probe configuration avoiding the contribution arising from electrode contact. Ease of fabrication, that is, controlled growth in both the horizontally and the vertically aligned direction is the added advantage. Although, various 1D nanomaterials-based sensors are reported; however, most of them are still in a noncommercial state. The reason for this could be assigned to the problems associated with them that includes nonuniform growth, poor control over density and distribution, reproducible contact with electrodes, and the sensor geometry.

\section{EN Based on Nanomaterials}

With the advancement in microelectromechanical systems (MEMS), nanoelectromechanical systems (NEMS) very large-scale integration (VLSI), and nanoscience various novel nanostructures are successfully being employed in the fabrication of EN device $[98,99]$. The smaller aspect ratio structures like nanoparticles (NPs), nanospheres, and nanocubes are generally used as a film for the sensing applications. On the other hand high aspect ratio structures have the potential to be incorporated singly, in multiples or as a film for sensing applications. The following section reviews the different ways in which nanomaterials can be used for EN applications. EN based on different nanomaterials, their detection principle and target molecules are summarized in Table 1.

5.1. Isolated and Single Nanostructures. One-dimensional structures are particularly important as they can be effectively utilized for developing EN based on single structures. The power requirement for single structure based devices is less $\sim$ few tens of microwatts and hence one can envisage the EN and energy harvesting devices on a single unit. Besides, the high aspect ratio and the variation along the length could effectively be used as variables resulting in individual and different sensing elements as demonstrated successfully by Sysoev et al. [100]. In particular, a simple and excellent performing EN based on single $\mathrm{SnO}_{2}$ nanobelt (NB) was realized using a combination of bottom-up fabrication protocols with the state-of-the art microfabrication methods. Figure 5(a) shows the schematic of the EN. The linear discriminate 
TABLE 1: EN based on different nanomaterials and their detection principle and target molecules.

\begin{tabular}{|c|c|c|c|c|}
\hline Sr. number & Sensing material & Target & Principle & References \\
\hline \multicolumn{5}{|c|}{ Single nanomaterial } \\
\hline 1 & $\mathrm{SnO}_{2} \mathrm{NB}$ & Ethanol, isopropyl alcohol, toluene, & Chemiresistive & [83-86] \\
\hline \multicolumn{5}{|c|}{ Multiple nanomaterial } \\
\hline 2 & Polypyrrole NTs & Helional gas & Chemiresistive & {$[176]$} \\
\hline 3 & Polypyrrole NTs & Amyl butyrate & FET & [177] \\
\hline \multicolumn{5}{|l|}{4} \\
\hline 5 & $\mathrm{SnO}_{2} \mathrm{NWs}$ & Ethanol, CO and 2-propanol & Chemiresistive & {$[87]$} \\
\hline 6 & $\mathrm{SnO}_{2} \mathrm{NWs}$ & Ethanol, Water & Chemiresistive & {$[178]$} \\
\hline 7 & $\begin{array}{c}\mathrm{SnO}_{2}, \mathrm{In}_{2} \mathrm{O}_{3} \text {, and } \mathrm{TiO}_{2} \\
\text { NWs }\end{array}$ & $\mathrm{H}_{2}, \mathrm{CO}$ & Chemiresistive & {$[179]$} \\
\hline 8 & $\mathrm{CNT}$ & Eugenol, 2-4 DNT, heptanal & FET & {$[180]$} \\
\hline 9 & $\mathrm{CNT}$ & $\begin{array}{l}\text { Amyl butyrate, pentyl valerate (PV), butyl butyrate } \\
\text { (BB), and propyl butyrate (PB) }\end{array}$ & FET & {$[181]$} \\
\hline \multicolumn{5}{|c|}{ Nanomaterials film } \\
\hline 10 & $\mathrm{ZnO} N P s$ & Chinese liquors & Chemiresistive & {$[182]$} \\
\hline 11 & $\mathrm{SnO}_{2} \mathrm{NPs}+\mathrm{Ag} / \mathrm{Pt}$ & $\mathrm{H}_{2}$ & Chemiresistive & {$[183]$} \\
\hline 12 & Graphene & Amyl butyrate & FET & [109] \\
\hline 13 & $\mathrm{Au}$ NPs & DNB, TNT, DNT & Chemiresistive & [184] \\
\hline 14 & Diamond NPs & DNT, DMMP, $\mathrm{NH}_{3}$ & SAW resonators & {$[185]$} \\
\hline 15 & Si-NWs & Cancerous cells & chemiresistive & {$[186]$} \\
\hline 16 & Si- NWs & TNT & FET & {$[187]$} \\
\hline \multicolumn{5}{|c|}{ Nanocomposites } \\
\hline 17 & $\mathrm{CNT}+\mathrm{SnO}_{2}$ & Whiskey, methanol & Chemiresistive & {$[188]$} \\
\hline 18 & $\mathrm{PNC}+\mathrm{CNT}$ & Water, toluene & Chemiresistive & [189] \\
\hline 19 & $\mathrm{PNC}$ & Lung cancer & Chemiresistive & [190] \\
\hline
\end{tabular}

analysis (LDA) performed over the responses from the EN successfully discriminated four gases, namely, ethanol, CO, isopropanol, and toluene as shown in Figure 5(b). The multisensor data related to different analytes are clearly separated from each other and the average Mahalanobis distance (MD) between analyte-dependent data clusters at the LDA feature space was $\sim 33$ units (Figure 5(c)). Additionally, the EN was demonstrated to detect low concentration complex aromatic compounds (glühwein, champagne, vermouth, and brandy) even under the strong background of ethanol.

Use of different type of sensing elements in the sensor array would lead to improvement in the selectivity as well as increase in the detection limits of target molecules. Recently, $\mathrm{Hu}$ et al. have developed a method to incorporate an array of single NWs; palladium (Pd), polypyrrole (PPy), polyaniline (PANI), and zinc oxide ( $\mathrm{ZnO})$ - from three material typesmetal, conducting polymer, and metal oxide-on a single chip as shown in Figure 6 [101]. Use of four different type of sensing elements facilitated a well separated sensing patterns for the detection of $\mathrm{CO}$, methanol, $\mathrm{NO}_{2}$, and $\mathrm{H}_{2}$ even at extremely low concentration levels (625 ppb).

The allotropes of carbon basically single walled nanotubes (SWNTs) and graphene have been widely investigated for possible chemical and biosensing applications [102].
Graphene is a two-dimensional (2D) crystalline monolayer made of $\mathrm{sp}^{2}$-hybridized carbon atoms arranged in a honeycomb lattice. In a way, it is the basic building block for all the other carbon nanomaterials. For example, folding up a graphene sheet into a cylinder along a certain lattice vector could result in the formation of SWNT [103]. Both these structures, namely, CNTs and graphene have the simplest chemical composition and atomic bonding configuration with higher surface area-to-volume ratio. This coupled with the size and surface comparable to the biomolecules has resulted in the detection limits down to single molecule levels $[104,105]$. Although, these structures have demonstrated a potential of single molecule detection they have not yet reached to the deliverable stage. This is predominantly because of the problems associated with the device-to-device heterogeneity arising from the variation in the morphology (diameter and aspect ratio), alignment, and accordingly receptor loading. Besides, this also raises a question over the possible system integration for uniform device array mass production [101].

5.2. Multiple Nanomaterials. Baik et al. have demonstrated an EN based on $\mathrm{SnO}_{2}$ multiple NW array (direct contact) using 


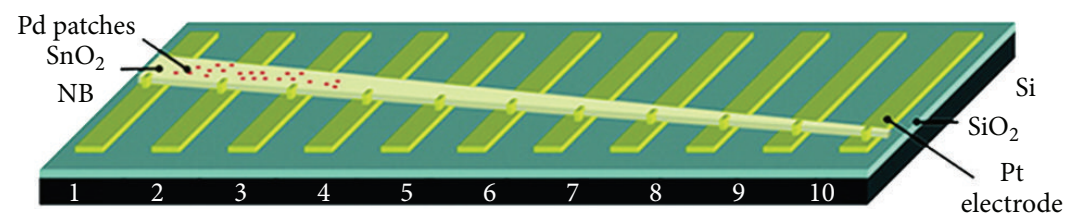

(a)

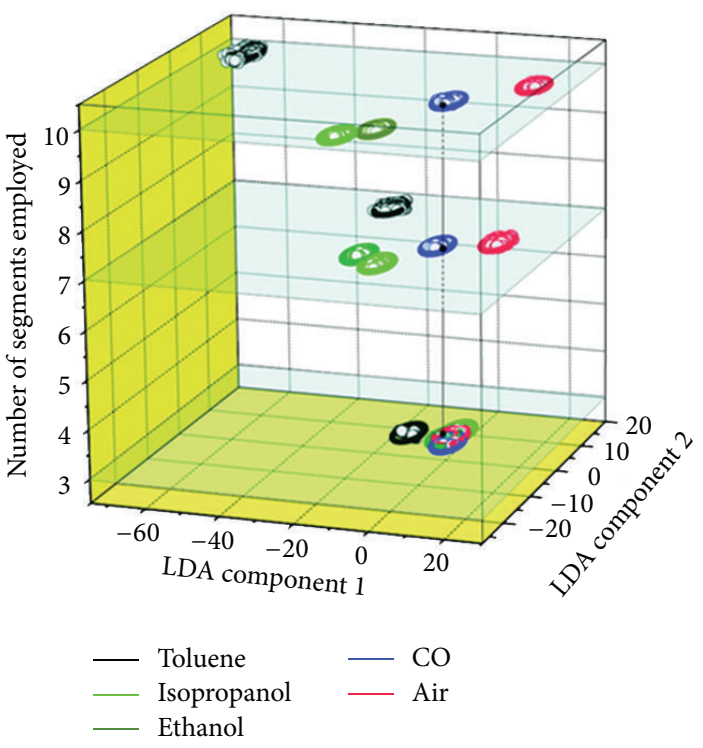

(b)

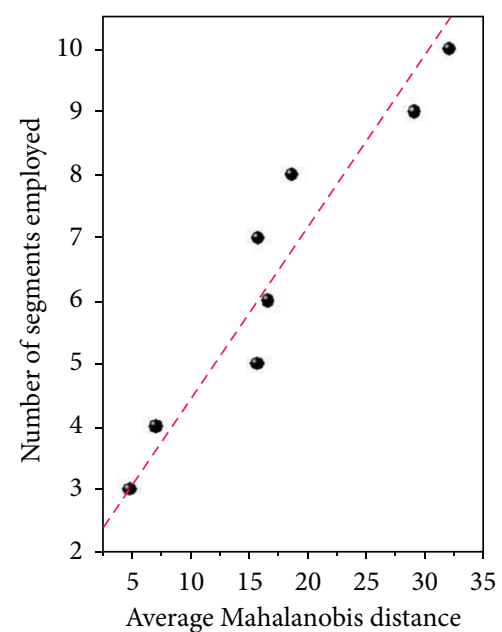

(c)

Figure 5: (a) The schematic presentation of the single NB EN and variation of the NB parameters along its length, (b) the LDA processing of the response of the single $\mathrm{SnO}_{2} \mathrm{NB}$ EN to the binary mixture of humidified $(\mathrm{RH}=50 \%)$ synthetic air with the analyte at 30 ppm concentration for four gases: ethanol, isopropyl alcohol, toluene, and CO. The classification LDA ellipses correspond to normal distribution of data at 0.99 confidence level. Top LDA plane corresponds to the processing of the response of all the $10 \mathrm{NB}$ segments to 5 gases, including the synthetic air; two other LDA planes have been built under a decreasing number of NB sensor (7 and 3) segments involved in the analysis. (c) The increase of Mahalanobis distance at the LDA feature space between data clusters related to various analytes versus number of NB sensor segments involved in the analysis. Published with permission from Sysoev et al. [100], Copyright @ 2013 American Chemical Society.

heterogeneous catalysis as functionalizing strategy as shown in Figure 7 [106]. Decorating the NWs surface with different metal nanoparticles is akin to functionalizing them with chemically specific moieties. The EN could unequivocally discriminate three gases, namely, $\mathrm{H}_{2}, \mathrm{CO}$, and $\mathrm{C}_{2} \mathrm{H}_{4}$ when the sensor responses were classified using linear discriminant analysis (LDA). $\mathrm{SnO}_{2} \mathrm{NWs}$ have also been used as gradient microarray sensors to realize EN [107]. The electronic nose systems were observed to detect and distinguish between reducing gases in air at ppb concentration level. The discriminating power of the system is defined by the density and morphological inhomogeneity of the NW array.

The unique anisotropic morphologies and the abundant structure tuning capabilities have led to a widespread investigation of Si-NWs-based sensing devices [108]. It is still the most prevalent electronic material compatible with most of the standard fabrication and processing techniques. Its diameter can easily be tuned to the scale of $10-100 \mathrm{~nm}$ which is comparable to many chemical and biological target molecules. It has been used in realizing optical/fluorescent sensing, noble metal-enabled surface enhanced Raman scattering (SERS) biosensing, and FET-based electrochemical and biosensing $[109,110]$. In case of FET-based sensing the surface of SiNWs serves as a gate which is modified with the receptors selective towards a particular biomolecule [111]. Attachment of biomolecule over the surfaces leads to a corresponding change in the carrier density inside the NWs. Using this simple approach detection of protein, $\mathrm{pH}$, biomarkers, peptides, and viral peptides have been demonstrated. A review by Wang et al. critically address the different sensors realized using SiNWs and the future of these devices [112].

5.3. Nanomaterials Film. The ability to precisely control the size, (monodispersity) shape, and functional groups on the surface of nanostructures has led to an upsurge in their use for sensing applications. Ibañez et al. have critically reviewed the chemiresistive sensors based on chemically modified metal and alloyed nanoparticles ([113, 114] and references within). In particular, sensing properties of metals such as $\mathrm{Au}, \mathrm{Pt}, \mathrm{Pd}$, $\mathrm{Ag}$, and alloys of these metals with several modifications have been explored, including functionalization with organic selfassembled monolayers (SAMs), polymers, surfactants, ions, and biomolecules, depending on the sensing application. Different methods have been used to realize a sensor, these 

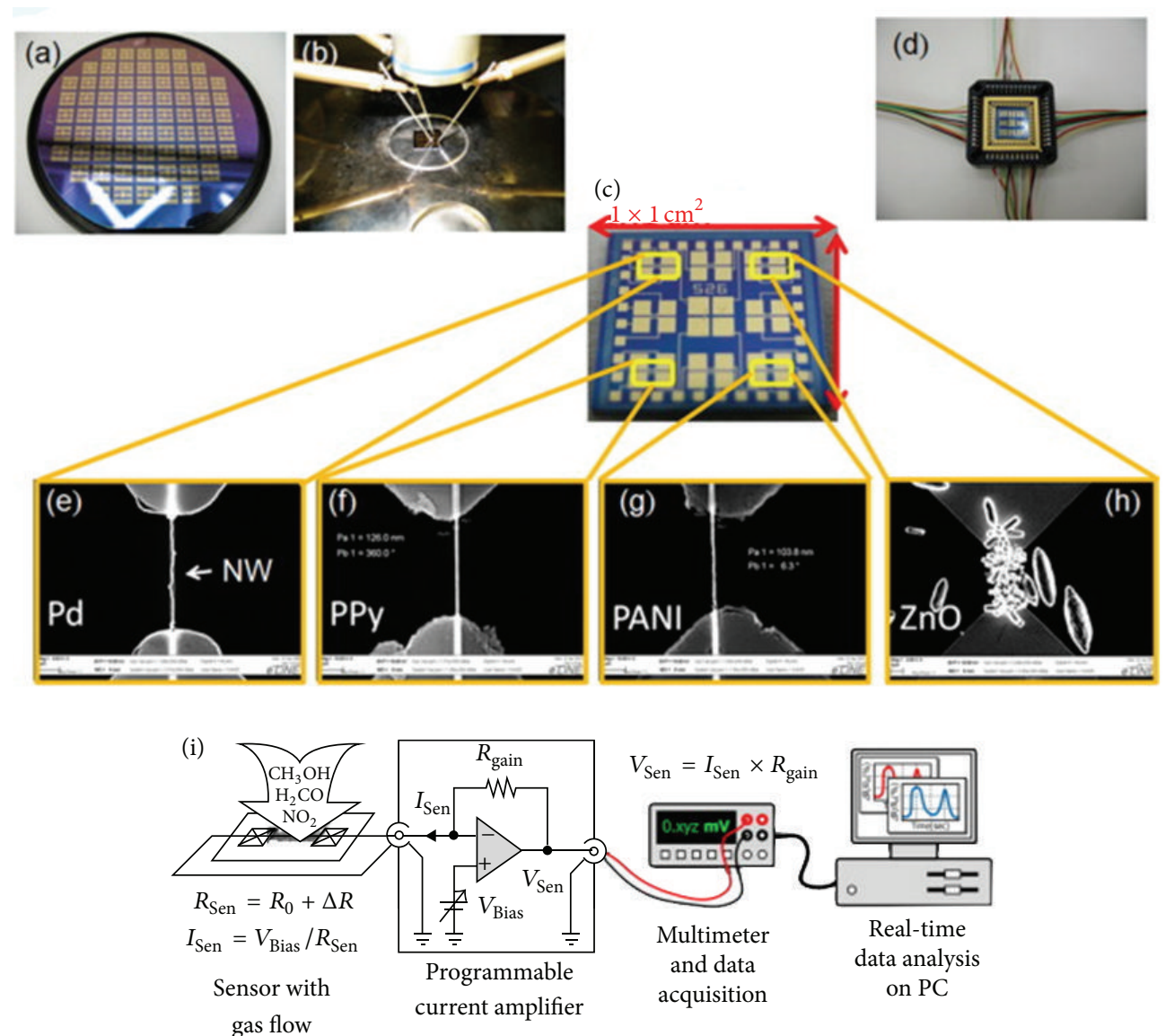

Figure 6: NW fabrication process and SEM images of synthesized single NWs. (a) 4 -in. Si wafer containing $69,1 \mathrm{~cm} \times 1 \mathrm{~cm}$ chips. (b) A chip placed under three probes of a probe station during NW electrochemical deposition. (c) Chip containing four different single NWs. (d) Sensor chip built on a chip with a single-NW array after wire bonding and integration. ((e)-(g)) SEM images of Pd, PPy, and PANI single NWs, respectively. The bright thin line denotes the NW, and the bright areas on top and bottom denote Ti/Au electrodes. (h) SEM image of ZnO NW. (i) Measurement setup for the read-out of sensor signal. Published with permission from Hu et al. [101] Copyright @ 2013 Elsevier.

include drop casting, air brushing, spin-coating, inkjet printing, microdispensing, immersion, microcontact printing, place-exchange cross-linking precipitation, and liquid phase cross-linking. Of the different NPs being investigated $\mathrm{Au}$ NPs have demonstrated a good potential to realize better sensors with tunable surface reactivity, that is, selectivity [115]. Recently, Broza et al. have demonstrated the feasibility of Au NPs- and Pt NPs-based chemiresistive sensors for identifying the breath-print of early-stage lung cancer (LC) and for shortterm followup after LC-resection [116]. The chemiresistive sensor were realized by drop-casting the solutions onto semicircular microelectronic transducers. Figure 8 shows the breadth print of early-stage malignant tumors: discriminant factor analysis of the sensing signals that were collected from the nanomaterial-based sensors before and after lung resection. There results clearly elucidate the fact that the NPs-based sensors do hold the potential for point of care diagnostics and medical care.

Additionally, $\mathrm{Au}$ NPs were also found to be useful for identification and generation of volatile fingerprints of cancer specific genetic mutations [117]. This work is of crucial significance as this may lead to the development of safer, prompt, and righteous interventions improving the quality of the treatment and end results. Kong et al. demonstrated that the fluorescence (FL) intensity of protein-directed synthesized Au NPs can be enhanced significantly (20-fold) on Ag plasmonic substrates [118]. Using this, a sensor array was developed that can successfully identify 10 kinds of protein. The protein analytes upon interaction with AuNPs influences the fluorescence process (decrease/increase) thereby providing distinct FL image patterns that can be used to identify and classify different protein molecules.

Chemiresistive FET based on other nanostructures, namely, carbon nanotubes (CNT), Si NWs, and Pt NPs have been shown to be effective in determination of VOCs released from the breadth associated with various diseases like lung, breast, colorectal, prostate, and colon cancer [119124]. On the similar context using SiNWs, Lieber et al. have demonstrated ultrasensitive real-time detection of various biological and chemical species including proteins, nucleic acids, small molecules, and viruses [125-127]. Conducting polymers especially NWs/NTs of polypyrrole, PEDOT, Pyrrole propylic acid (PPA), and P3CA have been found useful for the detection of cancer antigen 125 (CA125), thrombin 


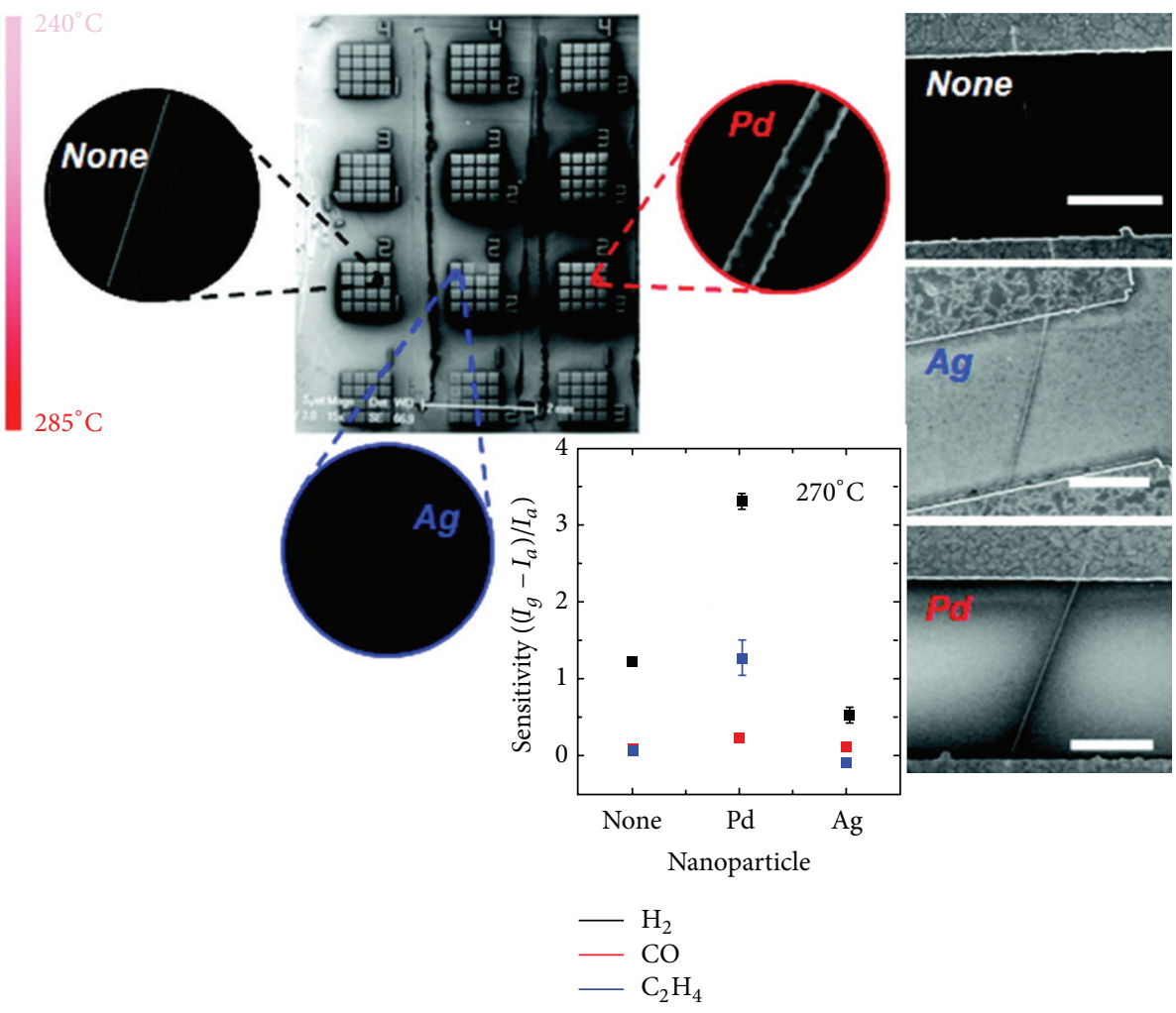

FIGURE 7: SEM image of the EN device showing the wire-bonding pads, which connect $\mathrm{SnO}_{2} \mathrm{NWs}$. A meander heater is incorporated into the chip at the bottom producing a $240-285^{\circ} \mathrm{C}$ temperature gradient in the vertical direction. SEM images of representative NWs (pristine, Pd-decorated, and Ag-decorated) are also shown as insets, as well as lower magnification images of the NWs (right-hand side) to show the manner in which they contact the pads. The scale bars are $10 \mathrm{~nm}$. The sensitivity of the individual sensors towards $\mathrm{H}_{2}, \mathrm{CO}, \mathrm{and}_{2} \mathrm{H}_{4} \mathrm{measured}$ at $270^{\circ} \mathrm{C}$ in a stream of flowing air $(10 \mathrm{sccm})$. Published with permission from Baik et al. [106], Copyright @ 2012 American Chemical Society.

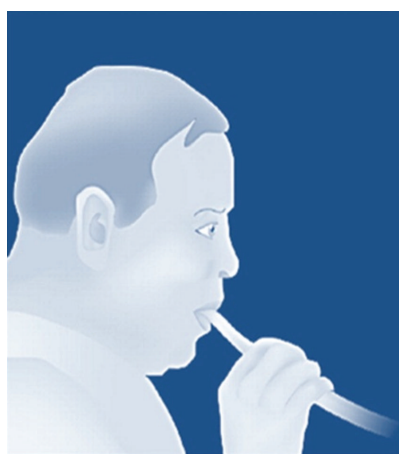

(a)

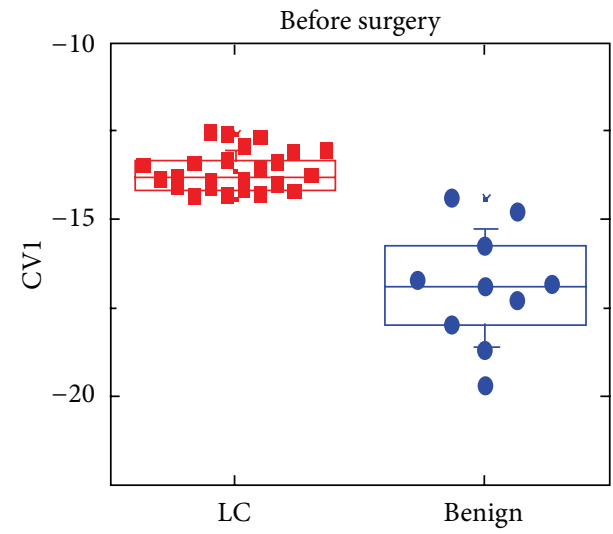

(b)

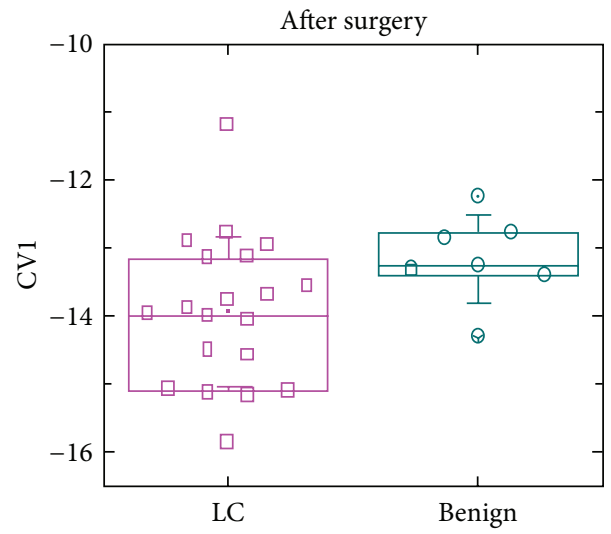

(c)

FiguRE 8: The breath print of early-stage malignant tumors: discriminant factor analysis of the sensing signals that were collected from the nanomaterial-based sensors before and after lung resection. Published with permission from Broza, [116], Copyright () 2013 Elsevier.

and human serum albumin, bacteriophages/viruses, DNA, spores, biotin, and glucose [128-130].

Nanomaterials-based chemiluminescence (CL) is also a promising and alternative technique that has been used effectively for determination of VOC's, sugars/artificial sweeteners, protein sensing, and cell discrimination [131-134].
Kong et al. have demonstrated a sensitive and reusable EN based on six catalytic nanomaterials, namely, $\mathrm{Pt} / \mathrm{Ba} / \mathrm{Al}, \mathrm{MgO}$, $\mathrm{ZrO}_{2}, \gamma-\mathrm{Al}_{2} \mathrm{O}_{3}, \mathrm{MgCO}_{3}$, and $\mathrm{SrCO}_{3}$ [131]. The CL efficiencies improve to varied degrees for a given protein or cell line on catalytic nanomaterials. Distinct CL response patterns as "fingerprints" were obtained on the array and then identified 


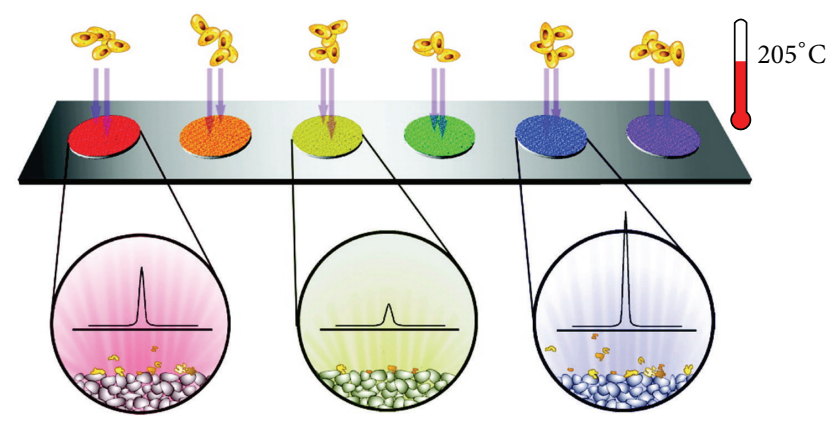

FIGURE 9: The schematic of the sensing process. The protein solutions or cell suspensions $(10 \mu \mathrm{L})$ are directly added on ceramic heaters sintered with catalytic nanomaterials. Then the proteins or cells are trapped onto the surface of nanomaterials after the volatilization of water. When the temperature is raised to $205^{\circ} \mathrm{C}$, analytes are thermally oxidized with the generation of distinct TCL. After TCL decays, remains of analytes are wiped out from the surface of nanomaterials at $500^{\circ} \mathrm{C}$. Published with permission from Kong et al. [131], Copyright (C) 2013 American Chemical Society.

through linear discriminant analysis (LDA). Figure 9 shows the schematics of the sensing process. The sensing of 12 kinds of proteins at three concentrations, as well as 12 types of human cell lines among normal, cancerous, and metastatic, has been successfully performed.

5.4. Conductive Polymer Nanocomposites. Nanomaterial incorporated polymer nanocomposites are one of the attractive class of materials for developing a room temperature sensors. Besides, room temperature operation they offer the advantages like light weight, inexpensive, possibility of control over the properties by adjustment of nanomaterial content, and chemical nature of the polymer matrix. Castro et al. have investigated the effect of amount of CNTs in the five different polymer matrices (polymer nanocomposites $[\mathrm{PNC}]$ ), namely, poly (caprolactone) (PCL), poly(lactic acid) (PLA), poly(carbonate) (PC), poly(methyl methacrylate) (PMMA), and a biobased polyester (BPR) on the responses towards VOCs [135]. The EN based on CNT-PNC could successfully distinguish the nine types of volatile organic compounds as shown in Figure 10.

Similarly, EN based on other polymer nanocomposite have been demonstrated to be successful in determination of lung cancer biomarkers, VOCs, alcohols, relative humidity, and metal ions in solution [136]. You et al. have demonstrated an $\mathrm{EN}$ based on $\mathrm{Au}$ NPs-fluorescent polymer conjugates that can detect, identify, and quantify protein targets in a rapid, efficient, and general fashion [137]. Figure 11 shows the basic principle involved in the detection. Presence of $\mathrm{Au}$ NPs quenches the polymer fluorescence and that of protein disrupts the Au NP and polymer interaction thereby resulting in a distinct fluorescence response pattern. Using an array of six noncovalent $\mathrm{Au}$ NP-fluorescent polymer (poly(p-phenyleneethynylene) (PPE) derivative, $\mathrm{PPE}-\mathrm{CO}_{2}$ ) conjugates, and LDA, 52 unknown protein samples (seven different proteins) with an accuracy of $94.2 \%$ as shown in Figure 11(b) were identified. The demonstrated method does not require any special instruments, and its sensitivity and speed facilitate protein detection.

5.5. Microcantilever-Based EN. A nanomechanical translation using cantilevers have been used as a common platform for the high throughput analysis such as protein, DNA, and cells. The cantilevers can be modified with receptor specific moieties and hence can result into sensors with high sensitivity, selectivity, and fast response kinetics. The binding of the analyte on the cantilever surface causes a shift in the resonant frequency. With advances in MEMS and NEMS, novel cantilever-based sensors have been fabricated with a potential to be incorporated in EN and exhibiting sensitivity down to zeptogram level $\left(1 \mathrm{zg}=10^{-21} \mathrm{gm}\right)[138$, 139]. Recently, Yang et al. have demonstrated a very high frequency silicon NW electrochemical resonators [138]. The epitaxially grown single crystal SiNWs were demonstrated to be a robust resonators operating at frequencies in very high frequency (VHF) range with high Q's (13100), zeptogram level mass sensitivity, and potential very large scale (VLS) device integration. Figure 12 shows the SEM image of one of the SiNW resonator.

Cantilever-based EN have also been demonstrated for successful determination of explosives like trinitrotoluene (TNT), dinitrotoluene (DNT), dinitrobenzene (DNB) [140, 141], hydrogen, primary alcohols, natural flavors, and water vapor $[142,143]$.

\section{State of the Art: Issues, Challenges, and Future Scope}

The prime outcome of the EN is the qualitative and quantitative determination of the odor, that is, information related to the type of gas/analyte and its concentration [144, 145]. To achieve the desired information there are various pattern recognition algorithms, available. The discrimination models include the common classifiers like nearest neighbor classifiers, local Euclidean distance templates, local Mahalanobis distance templates, multilayer perceptrons (MLPs), and support vector machines (SVMs) with Gaussian or polynomial kernels. Similarly, the quantification models are multivariate linear regressions, partial least squares regressions, multivariate quadratic regressions, MLPs, and SVMs. Very recently, Gao et al. have developed several types of hierarchical model and compared their capabilities for quantifying 12 kinds of volatile organic compounds with the improved electronic nose based on Taguchi gas sensors [146]. Their study indicated that the hierarchical model is composed of multiple single-output MLPs followed by multiple singleoutput MLPs with local decomposition, virtual balance and local generalization techniques, has advantages over the others in the aspects of time complexity, structure complexity and generalization performance.

Another challenge is the discrimination and quantification of odor existing in a very small concentration. A small concentration implies a high probability of strong interference from the other low or small concentration signals. This implies that the signal arising from different odors will lie 


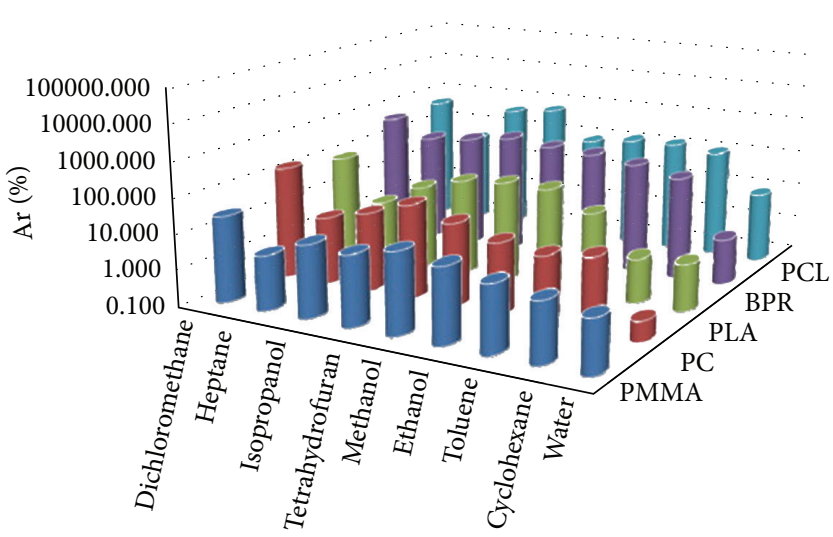

(a)

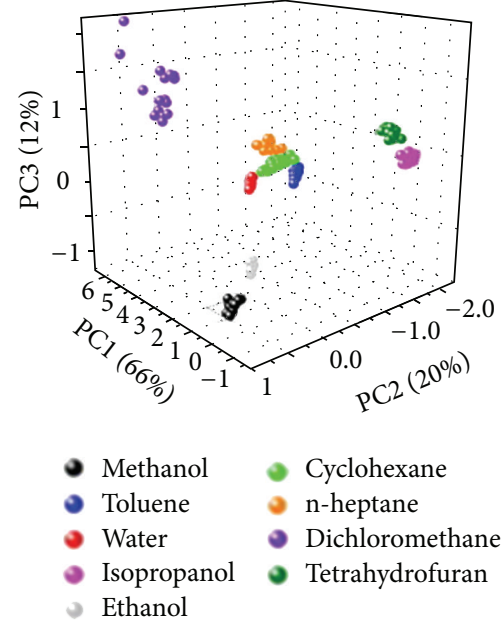

(b)

Figure 10: (a) Compared average selectivity over 15 cycles of the studied sensors when exposed to the selected solvent vapours and (b) results from the exposure of the 5-elements array to nine solvents in the first three dimensions of principal-component space. Published with permission from Castro et al. [135], Copyright (c) 2013 Elsevier.

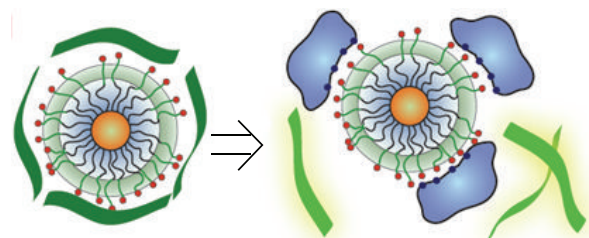

(a)

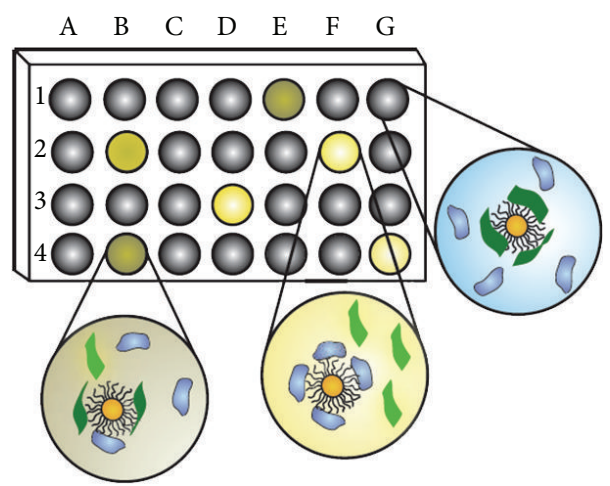

(b)

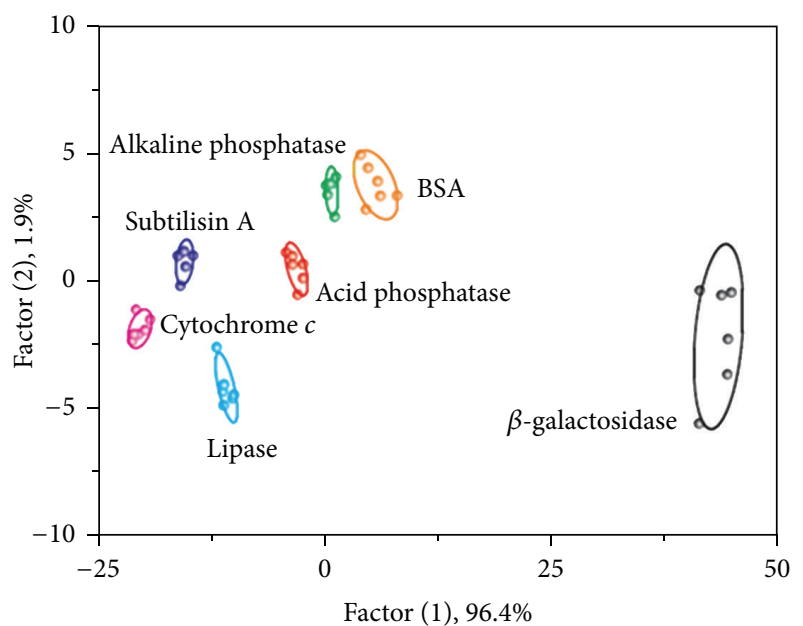

(c)

FIGURE 11: Fluorophore displacement protein sensor array. (a) Displacement of quenched fluorescent polymer (dark green strips, fluorescence off; light green strips, fluorescence on) by protein analyte (in blue) with concomitant restoration of fluorescence. The particle monolayers feature a hydrophobic core for stability, an oligo(ethylene glycol) layer for biocompatibility, and surface charged residues for interaction with proteins. (b) Fluorescence pattern generation through differential release of fluorescent polymers from gold nanoparticles. The wells on the microplate contain different nanoparticle-polymer conjugates, and the addition of protein analytes produces a fingerprint for a given protein. (c) Canonical score plot for the first two factors of simplified fluorescence response patterns obtained with NP-PPE assembly arrays against $5 \mathrm{mM}$ proteins. The canonical scores were calculated by LDA for the identification of seven proteins. The $95 \%$ confidence ellipses for the individual proteins are also shown. Published with permission from You et al. [137], Copyright (c) 2013 Nature Publishing Group.

close to or intersect with each other in the measured space. This will increase the complexity in successfully discriminating and quantifying a particular odor at the background of other odors [147] and hence demands an improvement in the existing sensors and pattern recognition algorithms $[148,149]$.

Another important challenge is to realize a contact to nanomaterials without altering the properties and if done 


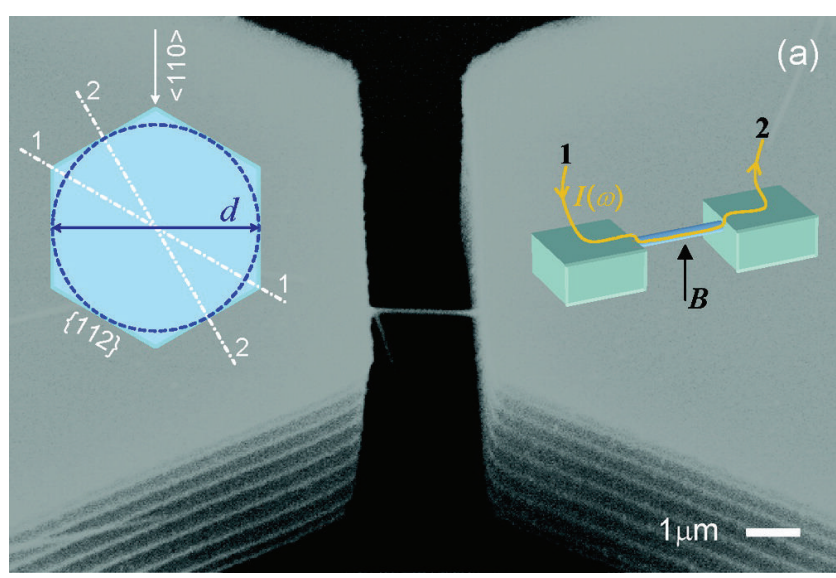

FIGURE 12: Scanning electron micrographs of pristine suspended SiNWs. (a) A typical silicon NW (SiNW) grown in a microtrench defined by two heavily doped supporting pads. Insets in (a) (left) orientation of the SiNW cross-section; (right) illustration of magnetomotive transduction of a SiNW. Published with permission from Yang et al. [138], Copyright (c) 2013 American Chemical Society.

then in a controlled way [150]. Additionally, the nanomaterials are functionalized using various organic molecules for generating the specific response and these organic molecules are prone to damage when attempted for electrical contacts. Recently, Haick et al. have reviewed the different ways to realize a contact on organic molecules with minimal and controlled alteration [151]. Various approaches including direct deposition of the conducting contact material on the molecules, using physical interactions and chemical bond formation between molecule and electrode materials, "readymade" contacts and contacts that are prepared in situ were explored and compared.

For realizing a complete lab-on-a-chip type EN requires a controlled analyte transport to the surface of nanomaterials through optimizing the flow patterns inside the microfluidic channel. This will assist in the reduction of the response time of biosensors [152]. Of the different processes, namely, fundamental surface reaction and convection and diffusion processes, enhancing the diffusional transport was found to improve the response kinetics.

All the above discussions clearly elucidates that nanomaterials do hold the promise for realizing an ultimate EN. However, before any practical or commercial application is envisaged it needs to address various daunting challenges. One of the important challenges is to gain complete understanding of the nanomaterials growth mechanism. This is crucial to achieve reproducible growth at predefined position with desired crystal quality and aspect ratio thereby assuring the repeatability and reproducibility of the EN. Controlled growth of metal NPs (e.g., Au), metal oxide NWs (e.g., ZnO), and organic NTs (CNT) has been achieved to a greater extend and accordingly are being widely employed.

The assembly of 1-D nanomaterials into ordered arrays is critical to the realization of integrated electronic architectures. Methodologies for development of large-scale hierarchical organization of nanomaterials arrays have been recently developed [153-158]. A review paper by Yu et al. discusses extensively different way of assembling NWs to achieve thin film ordering on microscale and corresponding device-based architectures $[159,160]$. However, one of the major disadvantages of the assembly techniques is that most of them are destructive in nature and the resultant alignment or assembly is not perfect. Moreover, nanomaterials in the final device are different thereby raising the question over reproducibility. It is thus crucial to come up with the solution wherein the nanomaterials can be assembled or aligned during the growth period itself $[161,162]$. Another important challenge is to align nanomaterials between predefined electrodes and form proper contacts which directly influences the performance of the device [163]. Using a VLS mechanism and conventional CMOS technology Pevzner et al. have demonstrated a confinement guided shaping of semiconductor NWs, which they refer to as "Writing with Nanowires" [164]. They have demonstrated the ability to get NWs in practically any desired shape and size and various substrates including silicon wafers, quartz, glass slides, and even on plastic substrates. This work is of critical importance and a valuable step towards achieving designer devices comprising NWs integrated to microstructures with desired and tunable properties. A review by Lee et al. discusses the recent progress in the development of integrated devices based on networks of NTs and NWs. The most commonly adopted methods for the integration includes directed assembly, printing, and directed growth. Recently, Min et al. have demonstrated a high-speed electrohydrodynamic organic NW printer to print large-area organic semiconducting NW arrays directly on device substrates in a precisely, individually controlled manner as shown in Figure 13 [165]. The method provides the advantage of high-speed, large-area printing of highly aligned individual or array of organic NWs that allows control of the exact numbers, position, and dimensions.

Now the most significant limitations for the widespread use of nanomaterial arises from the inability to grow them with industrial-scale production rate. It has been demonstrated that the well-adherent film of $\mathrm{ZnO}$ NWs could easily be grown on larger substrates sizes, $2^{\prime}-4^{\prime}$ with precise control over the aspect ratio using hydrothermal method [17, 109, 129]. Accordingly, the hydrothermal growth and other low temperature methods are also looked upon as a potential scale-up method. The larger substrate sizes could easily be coupled with the Si-microprocessing and microelectronics so as to realize commercial level devices. There are concerns related to the quality of the NWs resulting from this and other low temperature solution method. However, with appropriate modifications like postdeposition, annealing at higher temperature could possibly help to overcome the mentioned drawback. Very recently, Heurlin et al. have demonstrated a novel approach called "aerotaxy" from which production rates of GaAs NWs exceeding those available for substratenucleated NWs were achieved [166]. This continuous and potentially high-throughput method is expected substantially to reduce the cost of producing high-quality NWs and may enable the low-cost fabrication of NWs-based devices on an industrial-scale. A review by Fan et al. on the development of printable NWs-based electronics and sensors covers the 


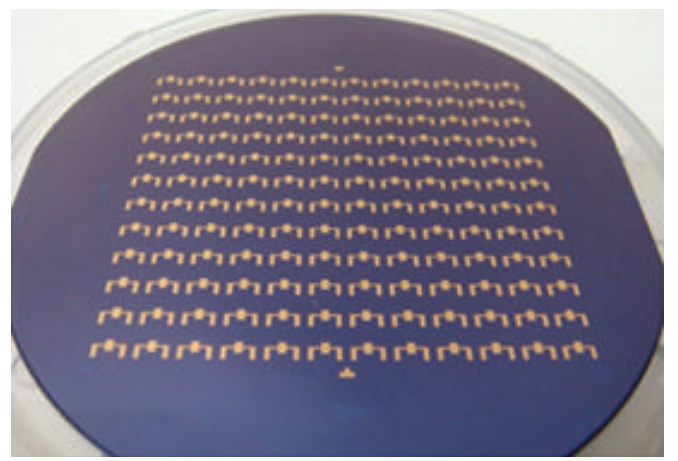

(a)

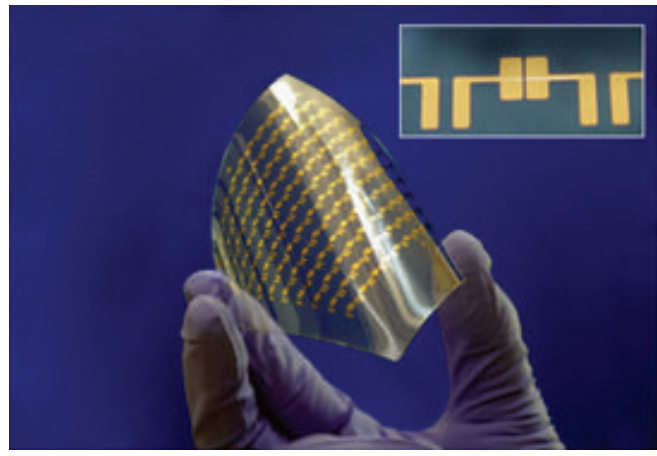

(c)

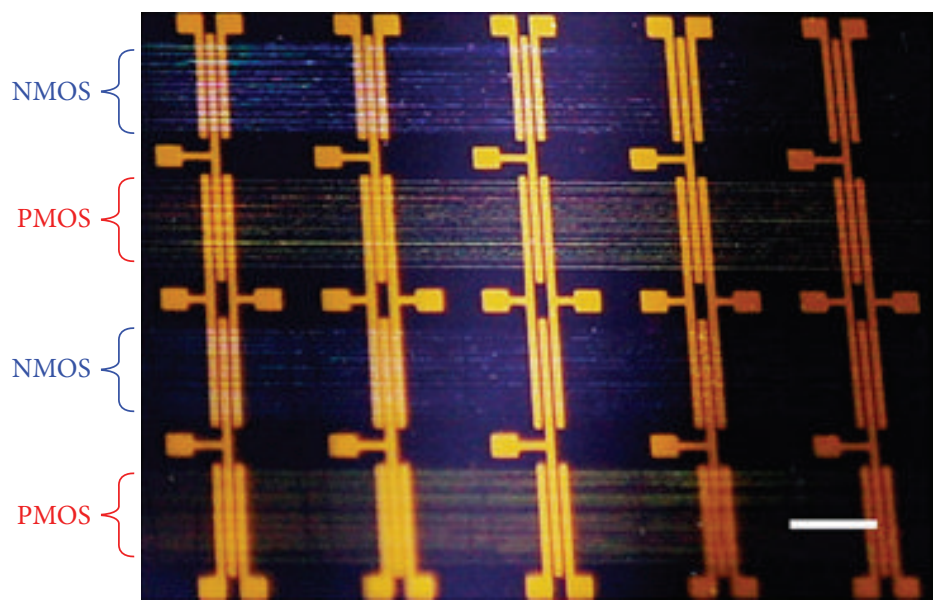

(e)

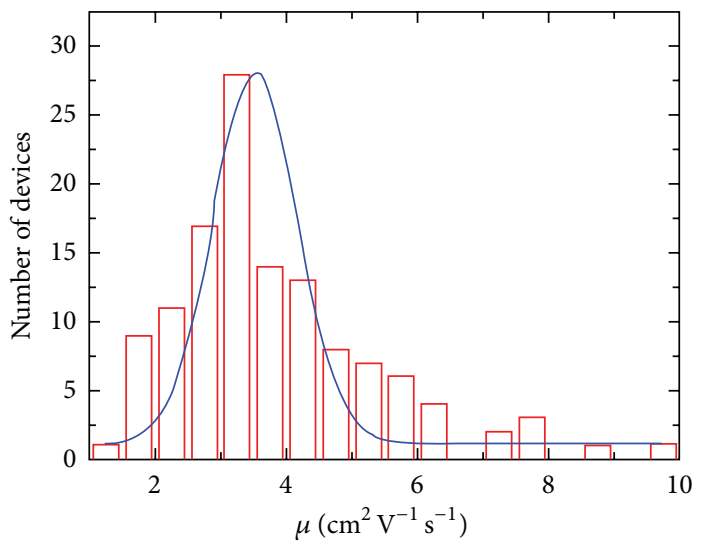

(b)

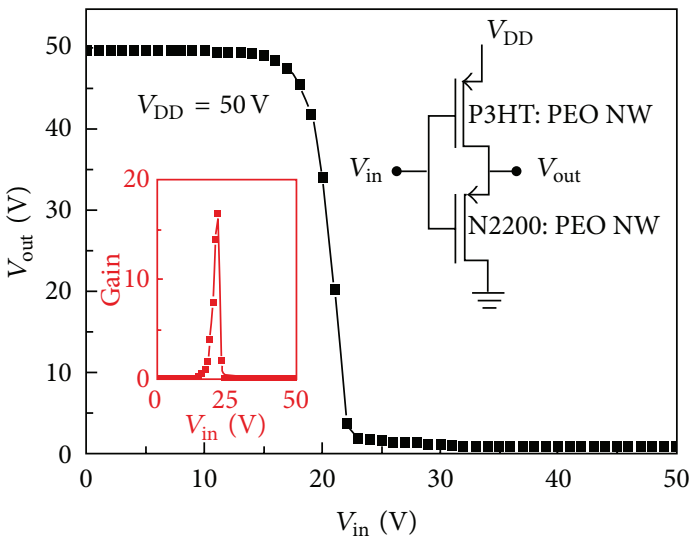

(d)

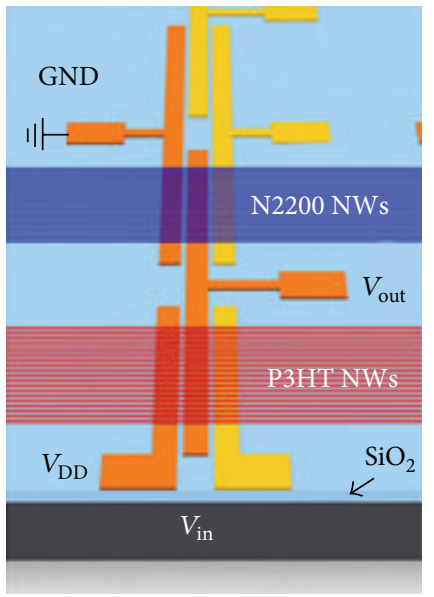

Figure 13: Large-area single P3HT:PEO-blend NW FET and complementary inverter circuit arrays. (a) Large-area single P3HT: PEO-blend $(70: 30$, w/w) NW FET array $(7 \mathrm{~cm} \times 7 \mathrm{~cm})$ with $\sim 300-\mathrm{nm}$ channel length (144 bottom-contact devices). (b) Histogram of the mobility for large-area P3HT: PEO-blend NW FET array with an average of $3.8 \pm 1.6 \mathrm{~cm}^{2} \mathrm{~V}^{-1} \mathrm{~s}^{-1}$. (c) Large-area single P3HT: PEO-blend NW FET array on polyarylate (PAR) substrate. (d) Input-output voltage characteristic for complementary inverter circuit based on P3HT: PEO-blend NWs and N2200: PEO-blend NWs (inset: gain characteristics). (e) Optical image of inverter array (left, scale bar, 2 mm) and schematic illustration of an inverter (right). Published with permission from Min et al.[165], Copyright @ 2013 Nature Publishing Group. 


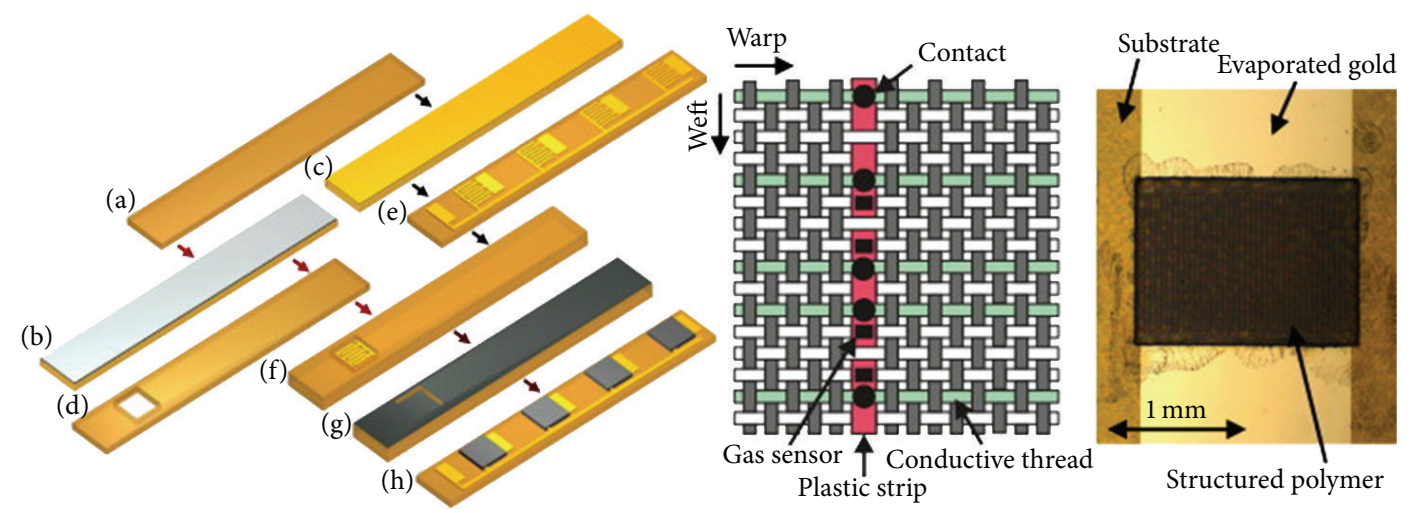

Figure 14: Illustration of the fabrication process (left), schematic graph of the electronic nose system woven into a textile (middle) and micrograph of a fabricated gas sensor using the mask lift-off technique (right). Published with permission from Kinkeldei et al. [173], Copyright $\odot 2013$ Elsevier.

different aspects and challenges involved in the field [167]. They have demonstrated the feasibility to realize the direct transfer and assembly of parallel-array NWs on various types of substrates by utilizing contact printing enabling the development of an all-printed technology for inorganic electronics and sensors.

As use of nanomaterials in the fabrication of $\mathrm{EN}$ is increasing, a demand over the development of the wireless EN sensor node is also increasing. The advantage of nanomaterials incorporation in particular the possible miniaturization raises the alarm over the use of conventional data acquisition system. Very recently, Bambang Dwi Kuncoro et al. have investigated the state of the art situation in development of the wireless EN sensor nodes [168]. Development in this direction is mainly characterized by the total power consumption, complexity, cost, and data acquisition rate. Recent technological advancements in the field of MEMS, NEMS, very large scale integration (VLSI), and wafer level $3 \mathrm{D}$ packaging have and are contributing towards the realization of miniaturized, low cost, and low power wireless EN sensor nodes. New idea is to use the energy harvesting as demonstrated successfully for $\mathrm{ZnO} \mathrm{NWs}$ for powering the miniaturized devices enabling self-powered devices [169].

Since the nanotechnology is revolutionizing at a greater speed the demand for EN with compatibility for flexible electronic devices is emerging. Nanomaterial does hold the promise for the same. Recently, Park et al. have demonstrated a ultrasensitive flexible graphene-based field-effect transistor(FET-) type bioelectronic nose [170]. The EN could recognize amyl butyrate with single carbon atom resolution having the detection limit of $0.04 \mathrm{fM}$. On the similar grounds Chou et al. have demonstrated a nanoscale grapheme oxide as artificial receptors for detection of protein molecules [171]. The developed EN could successfully differentiate the response from protein, namely, BSA, $\beta$-galactosidase $(\beta-\mathrm{Gal}$, from $E$. coli), hemoglobin (Hem, from equine heart), histone (His), lipase (Lip), lysozyme (Lys), myoglobin (Mayo), and ribonuclease A (Rib-A). Another interesting development is in the direction of EN system with textile integration. Such types of fabrics can be used in clothing to detect body parameters or as sensors in textiles to monitor the environment [172]. Kinkeldei et al. have demonstrated an incorporation of EN developed on flexible polymer substrate into a smart textile [173]. In particular, four carbon black/polymer gas sensors were first fabricated onto a flexible polymer substrate and then the substrate was cut into yarn like strips and integrated into a textile to create a smart textile with gas sensing functionalities. Figure 14 shows the steps involved in the fabrication of EN incorporated into textile. It was found that the harsh weaving conditions that bend the flexible polymer strip during fabrication (bending radii below $1 \mathrm{~mm}$ ) do not alter the sensor functionalities. Using the EN and the PCA four different solvents, namely, methanol, acetone, isopropanol (IPA), and toluene were easily differentiated. On the similar ground Han et al. have demonstrated a CNTbased $\mathrm{NH}_{3}$ sensor on a cotton textile [174]. These works are of critical importance as it demonstrated that sensor technologies can easily be integrated into the textiles with original sensor functionalities being preserved. The sensors embedded on garments are crucial in terms of designing a complete health care especially for the patients and the athletes [175].

All these results clearly demonstrate that the future of nanomaterials-based devices especially EN is very bright and a completely commercial device is within a reach and soon will be available in the market.

\section{Conclusions}

The faster reaction kinetics evident in nanomaterials hold the promise for fast and reliable sensors thereby enabling the realtime monitoring of various odors or gaseous species. Of the different ways in which nanomaterials are being employed for the fabrication of sensors, optical and chemiresistive sensors have demonstrated the potential for multiplex, label free, and real-time detection. The high surface area-to-volume ratio coupled with the tunable surface reactivity has resulted in 
sensors with near single molecule detection capacity with faster response kinetics. The possibility of high integration density leading to devices with smaller size and superior performance than the existing materials is the driving force behind the research performed for prospective commercial viability. The reproducible and reliable integration of nanomaterials in the actual devices and the device-to-device variation pose the threat to their ultimate commercial utility. However, recent studies have clearly indicated the possibility of overcoming the hurdles making the commercial viability within reach thereby opening the huge commercial market for nanomaterials-based EN devices.

\section{Acknowledgments}

Author would like to thank Dr. A. K. Debnath, Dr. D. K. Aswal (Head, TFDS/TPD), and Dr. S. K. Gupta (Head, TPD), for their kind help, support, and guidance. Also, Mr. C. P. Goyal, Mr. P. K. Sharma, Mr. V. R. Rikka, and Mr. S. K. Mishra are acknowledged for their assistance.

\section{References}

[1] J. W. Gardner and P. N. Bartlett, Eds., Sensors and Sensory Systems for the Electronic Nose, Kluwer Academic Publishers, London, UK, 1992.

[2] K. Persaud and G. Dodd, "Analysis of discrimination mechanisms in the mammalian olfactory system using a model nose," Nature, vol. 299, no. 5881, pp. 352-355, 1982.

[3] F. Röck, N. Barsan, and U. Weimar, "Electronic nose: current status and future trends," Chemical Reviews, vol. 108, no. 2, pp. 705-725, 2008.

[4] K. J. Albert, N. S. Lewis, C. L. Schauer et al., "Cross-reactive chemical sensor arrays," Chemical Reviews, vol. 100, no. 7, pp. 2595-2626, 2000.

[5] R. Glatz and K. Bailey-Hill, "Mimicking nature's noses: from receptor deorphaning to olfactory biosensing," Progress in Neurobiology, vol. 93, no. 2, pp. 270-296, 2011.

[6] S. Sankaran, L. R. Khot, and S. Panigrahi, "Biology and applications of olfactory sensing system: a review," Sensors and Actuators B, vol. 171-172, pp. 1-17, 2012.

[7] M. Peris and L. Escuder-Gilabert, "A 21st century technique for food control: electronic noses," Analytica Chimica Acta, vol. 638, no. 1, pp. 1-15, 2009.

[8] J. S. Vestergaard, M. Martens, and P. Turkki, "Application of an electronic nose system for prediction of sensory quality changes of a meat product (pizza topping) during storage," LWT-Food Science and Technology, vol. 40, no. 6, pp. 1095-1101, 2007.

[9] H. L. Gan, Y. B. Che Man, C. P. Tan, I. NorAini, and S. A. H. Nazimah, "Characterisation of vegetable oils by surface acoustic wave sensing electronic nose," Food Chemistry, vol. 89, no. 4, pp. 507-518, 2005.

[10] Å. Eriksson, K. P. Waller, K. Svennersten-Sjaunja, J.-E. Haugen, F. Lundby, and O. Lind, "Detection of mastitic milk using a gas-sensor array system (electronic nose)," International Dairy Journal, vol. 15, no. 12, pp. 1193-1201, 2005.

[11] H. Yu, J. Wang, H. Xiao, and M. Liu, "Quality grade identification of green tea using the eigenvalues of PCA based on the E-nose signals," Sensors and Actuators B, vol. 140, no. 2, pp. 378$382,2009$.
[12] V. Y. Musatov, V. V. Sysoev, M. Sommer, and I. Kiselev, "Assessment of meat freshness with metal oxide sensor microarray electronic nose: a practical approach," Sensors and Actuators B, vol. 144, no. 1, pp. 99-103, 2010.

[13] T. Dewettinck, K. van Hege, and W. Verstraete, "The electronic nose as a rapid sensor for volatile compounds in treated domestic wastewater," Water Research, vol. 35, no. 10, pp. 24752483, 2001.

[14] S. Zhang, C. Xie, D. Zeng, Q. Zhang, H. Li, and Z. Bi, "A feature extraction method and a sampling system for fast recognition of flammable liquids with a portable E-nose," Sensors and Actuators B, vol. 124, no. 2, pp. 437-443, 2007.

[15] A. Szczurek, P. M. Szecówka, and B. W. Licznerski, "Application of sensor array and neural networks for quantification of organic solvent vapours in air," Sensors and Actuators B, vol. 58, no. 1-3, pp. 427-432, 1999.

[16] A. C. Bastos and N. Magan, "Potential of an electronic nose for the early detection and differentiation between Streptomyces in potable water," Sensors and Actuators B, vol. 116, no. 1-2, pp. 151$155,2006$.

[17] L. Capelli, S. Sironi, P. Céntola, R. del Rosso, and M. Grande, "Electronic noses for the continuous monitoring of odours from a wastewater treatment plant at specific receptors: focus on training methods," Sensors and Actuators B, vol. 131, no. 1, pp. 53-62, 2008.

[18] E. Z. Panagou, N. Sahgal, N. Magan, and G.-J. E. Nychas, “Table olives volatile fingerprints: potential of an electronic nose for quality discrimination," Sensors and Actuators B, vol. 134, no. 2, pp. 902-907, 2008.

[19] R. Stella, J. N. Barisci, G. Serra, G. G. Wallace, and D. de Rossi, "Characterization of olive oil by an electronic nose based on conducting polymer sensors," Sensors and Actuators B, vol. 63, no. 1, pp. 1-9, 2000.

[20] H. Ulmer, J. Mitrovics, G. Noetzel, U. Weimar, and W. Göpel, "Odours and flavours identified with hybrid modular sensor systems," Sensors and Actuators B, vol. 43, no. 1-3, pp. 24-33, 1997.

[21] T. Nakamoto, A. Fukuda, and T. Moriizumi, "Perfume and flavor identification by odor-sensing system using quartzresonator sensor array and neural-network pattern recognition," Sensors and Actuators B, vol. 10, pp. 85-90, 1993.

[22] E. H. Oh, H. S. Song, and T. H. Park, "Recent advances in electronic and bioelectronic noses and their biomedical applications," Enzyme and Microbial Technology, vol. 48, no. 6-7, pp. 427-437, 2011.

[23] A. D’Amico, C. Di Natale, R. Paolesse et al., "Olfactory systems for medical applications," Sensors and Actuators B, vol. 130, no. 1, pp. 458-465, 2008.

[24] A. Lamagna, S. Reich, D. Rodriguez, and N. N. Scoccola, "Performance of an e-nose in hops classification," Sensors and Actuators B, vol. 102, no. 2, pp. 278-283, 2004.

[25] H. Knobloch, W. Schroedl, C. Turner, M. Chambers, and P. Reinhold, "Electronic nose responses and acute phase proteins correlate in blood using a bovine model of respiratory infection," Sensors and Actuators B, vol. 144, no. 1, pp. 81-87, 2010.

[26] H.-C. Chang, L. B. Kish, M. D. King, and C. Kwan, "Fluctuationenhanced sensing of bacterium odors," Sensors and Actuators B, vol. 142, no. 2, pp. 429-434, 2009.

[27] Z. Zheng and X. Lin, "Study on application of medical diagnosis by electronic nose," World Science and Technology, vol. 14, pp. 2115-2119, 2012. 
[28] T. Alizadeh and S. Zeynali, "Electronic nose based on the polymer coated SAW sensors array for the warfare agent simulants classification," Sensors and Actuators B, vol. 129, no. 1, pp. 412-423, 2008.

[29] D. Matatagui, J. Martí, M. J. Fernández et al., "Chemical warfare agents simulants detection with an optimized SAW sensor array," Sensors and Actuators B, vol. 154, no. 2, pp. 199-205, 2011.

[30] A. D. Wilson, "Review of electronic-nose technologies and algorithms to detect hazardous chemicals in the environment," Procedia Technology, vol. 1, pp. 453-463, 2012.

[31] B. Tudu, A. Jana, A. Metla, D. Ghosh, N. Bhattacharyya, and R. Bandyopadhyay, "Electronic nose for black tea quality evaluation by an incremental RBF network," Sensors and Actuators B, vol. 138, no. 1, pp. 90-95, 2009.

[32] N. H. Beltran, M. A. Duarte-Mermoud, V. A. Soto Vicencio, S. A. Salah, and M. A. Bustos, "Chilean wine classification using volatile organic compounds data obtained with a fast GC analyzer," IEEE Transactions on Instrumentation and Measurement, vol. 57, no. 11, pp. 2421-2436, 2008.

[33] J. A. Ragazzo-Sanchez, P. Chalier, D. Chevalier, M. CalderonSantoyo, and C. Ghommidh, "Identification of different alcoholic beverages by electronic nose coupled to GC," Sensors and Actuators B, vol. 134, no. 1, pp. 43-48, 2008.

[34] D. Cozzolino, W. Cynkar, R. Dambergs, and P. Smith, “Twodimensional correlation analysis of the effect of temperature on the fingerprint of wines analysed by mass spectrometry electronic nose," Sensors and Actuators B, vol. 145, no. 2, pp. 628634,2010

[35] L. Vera, L. Aceña, J. Guasch, R. Boqué, M. Mestres, and O. Busto, "Characterization and classification of the aroma of beer samples by means of an MS e-nose and chemometric tools," Analytical and Bioanalytical Chemistry, vol.399, no. 6, pp. 20732081, 2011.

[36] C. Li, P. Heinemann, and R. Sherry, "Neural network and Bayesian network fusion models to fuse electronic nose and surface acoustic wave sensor data for apple defect detection," Sensors and Actuators B, vol. 125, no. 1, pp. 301-310, 2007.

[37] H. Zhang, M. Chang, J. Wang, and S. Ye, "Evaluation of peach quality indices using an electronic nose by MLR, QPST and BP network," Sensors and Actuators B, vol. 134, no. 1, pp. 332-338, 2008.

[38] S. Panigrahi, S. Balasubramanian, H. Gu, C. Logue, and M. Marchello, "Neural-network-integrated electronic nose system for identification of spoiled beef," LWT-Food Science and Technology, vol. 39, no. 2, pp. 135-145, 2006.

[39] V. Y. Musatov, V. V. Sysoev, M. Sommer, and I. Kiselev, "Assessment of meat freshness with metal oxide sensor microarray electronic nose: a practical approach," Sensors and Actuators B, vol. 144, no. 1, pp. 99-103, 2010.

[40] N. E. Barbri, J. Mirhisse, R. Ionescu et al., "An electronic nose system based on a micro-machined gas sensor array to assess the freshness of sardines," Sensors and Actuators B, vol. 141, no. 2, pp. 538-543, 2009.

[41] M. A. Drake, P. D. Gerard, J. P. Kleinhenz, and W. J. Harper, "Application of an electronic nose to correlate with descriptive sensory analysis of aged Cheddar cheese," LWT-Food Science and Technology, vol. 36, no. 1, pp. 13-20, 2003.

[42] S. Ampuero and J. O. Bosset, "The electronic nose applied to dairy products: a review," Sensors and Actuators B, vol. 94, no. 1 , pp. 1-12, 2003.
[43] J. Orts, E. Llobet, X. Vilanova, J. Brezmes, and X. Correig, "Selective methane detection under varying moisture conditions using static and dynamic sensor signals," Sensors and Actuators B, vol. 60, no. 2, pp. 106-117, 1999.

[44] E. Llobet, J. Brezmes, X. Vilanova, J. E. Sueiras, and X. Correig, "Qualitative and quantitative analysis of volatile organic compounds using transient and steady-state responses of a thickfilm tin oxide gas sensor array," Sensors and Actuators B, vol. 41, no. 1-3, pp. 13-21, 1997.

[45] T. Šundić, S. Marco, A. Perera et al., "Fuzzy inference system for sensor array calibration: prediction of $\mathrm{CO}$ and $\mathrm{CH}_{4}$ levels in variable humidity conditions," Chemometrics and Intelligent Laboratory Systems, vol. 64, no. 2, pp. 103-122, 2002.

[46] B. Kateb, M. A. Ryan, M. L. Homer et al., "Sniffing out cancer using the JPL electronic nose: a pilot study of a novel approach to detection and differentiation of brain cancer," NeuroImage, vol. 47, no. 2, pp. T5-T9, 2009.

[47] D. L. García-González and R. Aparicio, "Sensors: from biosensors to the electronic nose," Grasas y Aceites, vol. 53, no. 1, pp. 96-114, 2002.

[48] R. Gutierrez-Osuna, Signal processing and pattern recognition for an electronic nose [Doctoral dissertation], North Carolina State University, 1998.

[49] H.-K. Hong, C. H. Kwon, S.-R. Kim, D. H. Yun, K. Lee, and Y. K. Sung, "Portable electronic nose system with gas sensor array and artificial neural network," Sensors and Actuators B, vol. 66, no. 1, pp. 49-52, 2000.

[50] A. Graves, M. Liwicki, S. Fernández, R. Bertolami, H. Bunke, and J. Schmidhuber, "A novel connectionist system for unconstrained handwriting recognition," IEEE Transactions on Pattern Analysis and Machine Intelligence, vol. 31, no. 5, pp. 855$868,2009$.

[51] J. Mitrovics, H. Ulmer, U. Weimar, and W. Göpel, "Modular sensor systems for gas sensing and odor monitoring: the Moses concept," Accounts of Chemical Research, vol. 31, no. 5, pp. 307315, 1998.

[52] J. Holova, O. Strouf, P. Zak et al., "QSAR of catechol analogs against malignant melanoma using fingerprint descriptors," Quantitative Structure-Activity Relationships, vol. 17, pp. 37-39, 1998.

[53] M. Vinaixa, S. Marín, J. Brezmes et al., "Early detection of fungal growth in bakery products by use of an electronic nose based on mass spectrometry," Journal of Agricultural and Food Chemistry, vol. 52, no. 20, pp. 6068-6074, 2004.

[54] C. S. Creaser, J. M. R. Griffiths, C. J. Bramwell, S. Noreen, C. A. Hill, and C. L. P. Thomas, "Ion mobility spectrometry: a review-part 1: structural analysis by mobility measurement," Analyst, vol. 129, no. 11, pp. 984-994, 2004.

[55] D. L. Massart, B. G. M. Vandeginste, L. M. C. Buydens, S. de Jong, P. J. Lewi, and J. Smeyers-Verbeke, Handbook of Chemometrics and Qualimetrics, Elsevier, Amsterdam, The Netherlands, 1998.

[56] F. Fenaille, P. Visani, R. Fumeaux, C. Milo, and P. A. Guy, "Comparison of mass spectrometry-based electronic nose and solid phase microextraction gas chromatography-mass spectrometry technique to assess infant formula oxidation," Journal of Agricultural and Food Chemistry, vol. 51, no. 9, pp. 2790-2796, 2003.

[57] E. J. Staples and S. Viswanathan, "Detection of contrabands in cargo containers using a high-speed gas chromatograph with surface acoustic wave sensor," Industrial and Engineering Chemical Research, vol. 47, no. 21, pp. 8361-8367, 2008. 
[58] S. Armenta, N. M. M. Coelho, R. Roda, S. Garrigues, and M. de la Guardia, "Seafood freshness determination through vapour phase Fourier transform infrared spectroscopy," Analytica Chimica Acta, vol. 580, no. 2, pp. 216-222, 2006.

[59] J. C. Tewari and J. M. K. Irudayaraj, "Floral classification of honey using mid-infrared spectroscopy and surface acoustic wave based z-Nose sensor," Journal of Agricultural and Food Chemistry, vol. 53, no. 18, pp. 6955-6966, 2005.

[60] A. Z. Berna, S. Trowell, W. Cynkar, and D. Cozzolino, "Comparison of metal oxide-based electronic nose and mass spectrometry-based electronic nose for the prediction of red wine spoilage," Journal of Agricultural and Food Chemistry, vol. 56, no. 9, pp. 3238-3244, 2008.

[61] O. R. Miranda, C.-C. You, R. Phillips et al., "Array-based sensing of proteins using conjugated polymers," Journal of the American Chemical Society, vol. 129, no. 32, pp. 9856-9857, 2007.

[62] A. J. Qavi, A. L. Washburn, J.-Y. Byeon, and R. C. Bailey, "Labelfree technologies for quantitative multiparameter biological analysis," Analytical and Bioanalytical Chemistry, vol. 394, no. 1, pp. 121-135, 2009.

[63] B. M. Rolfe, “Toward nanometer-scale sensing systems: natural and artificial noses as models for ultra-small, ultra-dense sensing systems," Advances in Computers, vol. 71, pp. 103-166, 2007.

[64] J. Henzie, J. E. Barton, C. L. Stender, and T. W. Odom, "Large-area nanoscale patterning: chemistry meets fabrication," Accounts of Chemical Research, vol. 39, no. 4, pp. 249-257, 2006.

[65] C. M. Hangarter, M. Bangar, A. Mulchandani, and N. V. Myung, "Conducting polymer nanowires for chemiresistive and FETbased bio/chemical sensors," Journal of Materials Chemistry, vol. 20, no. 16, pp. 3131-3140, 2010.

[66] Y. Li, F. Qian, J. Xiang, and C. M. Lieber, "Nanowire electronic and optoelectronic devices," Materials Today, vol. 9, no. 10, pp. $18-27,2006$.

[67] A. I. Hochbaum and P. Yang, "Semiconductor nanowires for energy conversion," Chemical Reviews, vol. 110, no. 1, pp. 527$546,2010$.

[68] R. K. Joshi, Q. Hu, F. Alvi, N. Joshi, and A. Kumar, "Au decoratedzinc oxide nanowires for CO sensing," The Journal of Physical Chemistry C, vol. 113, no. 36, pp. 16199-16202, 2009.

[69] W.-K. Hong, J. I. Sohn, D.-K. Hwang et al., "Tunable electronic transport characteristics of surface-architecturecontrolled $\mathrm{ZnO}$ nanowire field effect transistors," Nano Letters, vol. 8, no. 3, pp. 950-956, 2008.

[70] N. S. Ramgir, Y. Yang, and M. Zacharias, "Nanowire-based sensors," Small, vol. 6, no. 16, pp. 1705-1722, 2010.

[71] J. Huang and Q. Wan, "Gas sensors based on semiconducting metal oxide one-dimensional nanostructures," Sensors, vol. 9, no. 12, pp. 9903-9924, 2009.

[72] A. Afzal, N. Cioffi, L. Sabbatini, and L. Torsi, "NO${ }_{x}$ sensors based on semiconducting metal oxide nanostructures: progress and perspectives," Sensors and Actuators B, vol. 171-172, pp. 2542, 2012.

[73] D. K. Aswal and S. K. Gupta, Eds., Science and Technology of Chemiresistive Gas Sensors, Nova Science Publisher, New York, NY, USA, 2007.

[74] N. S. Ramgir, N. Datta, M. Kaur, A. K. Debnath, D. K. Aswal, and S. K. Gupta, "Semiconductor nanowires and heterostructures based gas sensors," in Nanowires: Properties, Synthesis and Applications, V. Lefevre, Ed., pp. 1-46, Nova Science Publisher, New York, NY, USA, 2011.
[75] N. Yamazoe, "Toward innovations of gas sensor technology," Sensors and Actuators B, vol. 108, no. 1-2, pp. 2-14, 2005.

[76] G. Bläser, T. Rühl, C. Diehl, M. Ulrich, and D. Kohl, "Nanostructured semiconductor gas sensors to overcome sensitivity limitations due to percolation effects," Physica A, vol. 266, no. 1-4, pp. 218-223, 1999.

[77] A. Gurlo, M. Ivanovskaya, N. Bârsan et al., "Grain size control in nanocrystalline $\mathrm{In}_{2} \mathrm{O}_{3}$ semiconductor gas sensors," Sensors and Actuators B, vol. 44, no. 1-3, pp. 327-333, 1997.

[78] W. Göpel and K. D. Schierbaum, " $\mathrm{SnO}_{2}$ sensors: current status and future prospects," Sensors and Actuators B, vol. 26, no. 1-3, pp. 1-12, 1995.

[79] R. Gross and L. Tagirov, Eds., Nanoscale Devices-Fundamental and Applications, Springer, Dordrecht, The Netherlands, 2006.

[80] Z. L. Wang, "Splendid one-dimensional nanostructures of zinc oxide: a new nanomaterial family for nanotechnology," ACS Nano, vol. 2, no. 10, pp. 1987-1992, 2008.

[81] X. Yan, Z. Li, C. Zou et al., "Renucleation and sequential growth of $\mathrm{ZnO}$ complex nano/microstructure: from nano/microrod to ball-shaped cluster," Journal of Physical Chemistry C, vol. 114, no. 3, pp. 1436-1443, 2010.

[82] N. S. Ramgir, V. Rikka, M. Kaur et al., " $\mathrm{ZnO}$ nanowires as $\mathrm{H}_{2} \mathrm{~S}$ sensor," in Proceedings of the International Conference on Physics of Emerging Functional Materials (PEFM '10), D. K. Aswal and A. K. Debnath, Eds., pp. 322-324, September 2010.

[83] Z. L. Wang, "Novel nanostructures of $\mathrm{ZnO}$ for nanoscale photonics, optoelectronics, piezoelectricity, and sensing," Applied Physics A, vol. 88, no. 1, pp. 7-15, 2007.

[84] C. N. R. Rao, F. L. Deepak, G. Gundiah, and A. Govindaraj, "Inorganic nanowires," Progress in Solid State Chemistry, vol. 31, no. 1-2, pp. 5-147, 2003.

[85] L. E. Greene, B. D. Yuhas, M. Law, D. Zitoun, and P. Yang, "Solution-grown zinc oxide nanowires," Inorganic Chemistry, vol. 45, no. 19, pp. 7535-7543, 2006.

[86] M. Law, J. Goldberger, and P. Yang, "Semiconductor nanowires and nanotubes," Annual Review of Materials Research, vol. 34, pp. 83-122, 2004.

[87] R. L. Vander Wal, G. W. Hunter, J. C. Xu, M. J. Kulis, G. M. Berger, and T. M. Ticich, "Metal-oxide nanostructure and gassensing performance," Sensors and Actuators B, vol. 138, no. 1, pp. 113-119, 2009.

[88] G. Korotcenkova and B. K. Cho, "The role of grain size on the thermal instability of nanostructured metal oxides used in gas sensor applications and approaches for grain-size stabilization," Progress in Crystal Growth and Characterization of Materials, vol. 58, no. 4, pp. 167-208, 2012.

[89] C. Xu, J. Tamaki, N. Miura, and N. Yamazoe, "Stabilization of $\mathrm{SnO}_{2}$ ultrafine particles by additives," Journal of Materials Science, vol. 27, no. 4, pp. 963-971, 1992.

[90] A. Tricoli, M. Graf, and S. E. Pratsinis, "Optimal doping for enhanced $\mathrm{SnO}_{2}$ sensitivity and thermal stability," Advanced Functional Materials, vol. 18, no. 13, pp. 1969-1976, 2008.

[91] G. Korotcenkov, B. K. Cho, M. Nazarov, D. Y. Noh, and E. V. Kolesnikova, "Cathodoluminescence studies of un-doped and $(\mathrm{Cu}, \mathrm{Fe}$, and $\mathrm{Co}$ )-doped tin dioxide films deposited by spray pyrolysis," Current Applied Physics, vol. 10, no. 4, pp. 1123-1131, 2010.

[92] B. Chitara, D. J. Late, S. B. Krupanidhi, and C. N. R. Rao, "Roomtemperature gas sensors based on gallium nitride nanoparticles," Solid State Communications, vol. 150, no. 41-42, pp. $2053-$ 2056, 2010. 
[93] A. A. Tomchenko, G. P. Harmer, B. T. Marquis, and J. W. Allen, "Semiconducting metal oxide sensor array for the selective detection of combustion gases," Sensors and Actuators B, vol. 93, no. 1-3, pp. 126-134, 2003.

[94] K. D. Mitzner, J. Sternhagen, and D. W. Galipeau, "Development of a micromachined hazardous gas sensor array," Sensors and Actuators B, vol. 93, no. 1-3, pp. 92-99, 2003.

[95] J. Wollenstein, J. A. Plaza, C. Cane, Y. Min, H. Botttner, and H. L. Tuller, "A novel single chip thin film metal oxide array," Sensors and Actuators B, vol. 93, no. 1-3, pp. 350-355, 2003.

[96] B. W. Mwakikunga, S. Motshekga, L. Sikhwivhilu et al., "A classification and ranking system on the $\mathrm{H}_{2}$ gas sensing capabilities of nanomaterials based on proposed coefficients of sensor performance and sensor efficiency equations," Sensors and Actuators B, vol. 184, pp. 170-178, 2013.

[97] A. Liu, "Towards development of chemosensors and biosensors with metal-oxide-based nanowires or nanotubes," Biosensors and Bioelectronics, vol. 24, no. 2, pp. 167-177, 2008.

[98] D. James, S. M. Scott, Z. Ali, and W. T. O’Hare, "Review chemical sensors for electronic nose systems," Microchimica Acta, vol. 149, no. 1-2, pp. 1-17, 2005.

[99] J. Wang and X. Qu, "Recent progress in nanosensors for sensitive detection of biomolecules," Nanoscale, vol. 5, no. 9, pp. 3589-3600, 2013.

[100] V. V. Sysoev, E. Strelcov, M. Sommer et al., "Single-nanobelt electronic nose: engineering and tests of the simplest analytical element," ACS Nano, vol. 4, no. 8, pp. 4487-4494, 2010.

[101] Y. Hu, H. Lee, S. Kim, and M. Yun, "A highly selective chemical sensor array based on nanowire/nanostructure for gas identification," Sensors and Actuators B, vol. 181, pp. 424-431, 2013.

[102] S. Liu and X. Guo, "Carbon nanomaterials field-effect-transistor-based Biosensors," NPG Asia Materials, vol. 4, p. e23, 2012.

[103] Y. Ohno, K. Maehashi, and K. Matsumoto, "Chemical and biological sensing applications based on graphene field-effect transistors," Biosensors and Bioelectronics, vol. 26, no. 4, pp. 1727-1730, 2010.

[104] X. Huang, Z. Yin, S. Wu et al., "Graphene-based materials: synthesis, characterization, properties, and applications," Small, vol. 7, no. 14, pp. 1876-1902, 2011.

[105] F. Schedin, A. K. Geim, S. V. Morozov et al., "Detection of individual gas molecules adsorbed on graphene," Nature Materials, vol. 6, no. 9, pp. 652-655, 2007.

[106] J. M. Baik, M. Zielke, M. H. Kim, K. L. Turner, A. M. Wodtke, and M. Moskovits, "Tin-oxide-nanowire-based electronic nose using heterogeneous catalysis as a functionalization strategy," ACS Nano, vol. 4, no. 6, pp. 3117-3122, 2010.

[107] V. V. Sysoev, J. Goschnick, T. Schneider, E. Strelcov, and A. Kolmakov, "A gradient microarray electronic nose based on percolating $\mathrm{SnO}_{2}$ nanowire sensing elements," Nano Letters, vol. 7, no. 10, pp. 3182-3188, 2007.

[108] C. M. Lieber, "Nanoscale science and technology: building a big future from small things," MRS Bulletin, vol. 28, no. 7, pp. 486491, 2003.

[109] A. M. Morales and C. M. Lieber, "A laser ablation method for the synthesis of crystalline semiconductor nanowires," Science, vol. 279, no. 5348, pp. 208-211, 1998.

[110] V. Schmidt, J. V. Wittemann, S. Senz, and U. Gösele, "Silicon nanowires: a review on aspects of their growth and their electrical properties," Advanced Materials, vol. 21, no. 25-26, pp. 2681-2702, 2009.
[111] Y. F. Zhang, Y. H. Tang, N. Wang et al., "Silicon nanowires prepared by laser ablation at high temperature," Applied Physics Letters, vol. 72, no. 15, pp. 1835-1837, 1998.

[112] Y. Wang, T. Wang, P. Da, M. Xu, H. Wu, and G. Zheng, "Silicon nanowires for biosensing, energy storage, and conversion," Advanced Materials, vol. 25, no. 37, pp. 5177-5195, 2013.

[113] F. J. Ibañez and F. P. Zamborini, "Chemiresistive sensing with chemically modified metal and alloy nanoparticles," Small, vol. 8, no. 2, pp. 174-202, 2012.

[114] H. Jans and Q. Huo, "Gold nanoparticle-enabled biological and chemical detection and analysis," Chemical Society Reviews, vol. 41, no. 7, pp. 2849-2866, 2012.

[115] K. Saha, S. S. Agasti, C. Kim, X. Li, and V. M. Rotello, "Gold nanoparticles in chemical and biological sensing," Chemical Reviews, vol. 112, no. 5, pp. 2739-2779, 2012.

[116] Y. Y. Broza, R. Kremer, U. Tisch et al., "A nanomaterial-based breath test for short-term follow-up after lung tumor resection," Nanomedicine: Nanotechnology, Biology and Medicine, vol. 9, no. 1, pp. 15-21, 2013.

[117] N. Peled, O. Barash, U. Tisch et al., "Volatile fingerprints of cancer specific genetic mutations," Nanomedicine: Nanotechnology, Biology and Medicine, vol. 9, no. 6, pp. 758-766, 2013.

[118] H. Kong, Y. Lu, H. Wang, F. Wen, S. Zhang, and X. Zhang, "Protein discrimination using fluorescent gold nanoparticles on plasmonic substrates," Analytical Chemistry, vol. 84, no. 10, pp. 4258-4261, 2012.

[119] U. Tisch and H. Haick, "Arrays of nanomaterial-based sensors for breath testing," in Volatile Biomarkers: Non-Invasive Diagnosis in Physiology and Medicine, chapter 16, pp. 301-323, Elsevier, Amsterdam, The Netherlands, 2013.

[120] O. Barash, N. Peled, F. R. Hirsch, and H. Haick, "Sniffing the unique "odor print" of non-small-cell lung cancer with gold nanoparticles," Small, vol. 5, no. 22, pp. 2618-2624, 2009.

[121] M. Y. Bashouti, K. Sardashti, S. W. Schmitt et al., "Oxidefree hybrid silicon nanowires: from fundamentals to applied nanotechnology," Progress in Surface Science, vol. 88, pp. 39-60, 2013.

[122] O. Barash, N. Peled, U. Tisch, P. A. Bunn Jr., F. R. Hirsch, and H. Haick, "Classification of lung cancer histology by gold nanoparticle sensors," Nanomedicine: Nanotechnology, Biology, and Medicine, vol. 8, pp. 580-589, 2012.

[123] G. Peng, M. Hakim, Y. Y. Broza et al., "Detection of lung, breast, colorectal, and prostate cancers from exhaled breath using a single array of nanosensors," British Journal of Cancer, vol. 103, no. 4, pp. 542-551, 2010.

[124] U. Tisch, S. Billan, M. Ilouze, M. Phillips, N. Peled, and H. Haick, "Volatile organic compounds in the exhaled breath as biomarkers for the early detection and screening of lung cancer," CML-Lung Cancer, vol. 5, pp. 107-117, 2012.

[125] F. Patolsky, G. Zheng, and C. M. Lieber, "Fabrication of silicon nanowire devices for ultrasensitive, label-free, real-time detection of biological and chemical species," Nature Protocols, vol. 1, no. 4, pp. 1711-1724, 2006.

[126] G. Zheng and C. M. Lieber, "Nanowire biosensors for labelfree, real-time, ultrasensitive protein detection," Methods in Molecular Biology, vol. 790, pp. 223-237, 2011.

[127] C. M. Lieber, "Semiconductor nanowires: a platform for nanoscience and nanotechnology," MRS Bulletin, vol. 36, no. 12, pp. 1052-1063, 2011.

[128] A. Mulchandani and N. V. Myung, "Conducting polymer nanowires-based label-free biosensors," Current Opinion in Biotechnology, vol. 22, no. 4, pp. 502-508, 2011. 
[129] H. Yoon, S. Ko, and J. Jang, "Field-effect-transistor sensor based on enzyme-functionalized polypyrrole nanotubes for glucose detection," Journal of Physical Chemistry B, vol. 112, no. 32, pp. 9992-9997, 2008.

[130] J. A. Arter, D. K. Taggart, T. M. McIntire, R. M. Penner, and G. A. Weiss, "Virus-PEDOT nanowires for biosensing," Nano Letters, vol. 10, no. 12, pp. 4858-4862, 2010.

[131] H. Kong, D. Liu, S. Zhang, and X. Zhang, "Protein sensing and cell discrimination using a sensor array based on nanomaterialassisted chemiluminescence," Analytical Chemistry, vol. 83, no. 6, pp. 1867-1870, 2011.

[132] W. Niu, H. Kong, H. Wang, Y. Zhang, S. Zhang, and X. Zhang, "A chemiluminescence sensor array for discriminating natural sugars and artificial sweeteners," Analytical and Bioanalytical Chemistry, vol. 402, no. 1, pp. 389-395, 2012.

[133] W. Niu, "A chemiluminescence sensor array based on nanomaterials for discrimination of teas," Luminescence, vol. 28, no. 2, pp. 239-243, 2013.

[134] T. Asefa, C. T. Duncan, and K. K. Sharma, "Recent advances in nanostructured chemosensors and biosensors," Analyst, vol. 134, no. 10, pp. 1980-1990, 2009.

[135] M. Castro, B. Kumar, J. F. Feller, Z. Haddi, A. Amari, and B. Bouchikhi, "Novel e-nose for the discrimination of volatile organic biomarkers with an array of carbon nanotubes (CNT) conductive polymer nanocomposites (CPC) sensors," Sensors and Actuators B, vol. 159, no. 1, pp. 213-219, 2011.

[136] T. Asefa, C. T. Duncan, and K. K. Sharma, "Recent advances in nanostructured chemosensors and biosensors," Analyst, vol. 134, no. 10, pp. 1980-1990, 2009.

[137] C.-C. You, O. R. Miranda, B. Gider et al., "Detection and identification of proteins using nanoparticle-fluorescent polymer 'chemical nose' sensors,' Nature Nanotechnology, vol. 2, no. 5, pp. 318-323, 2007.

[138] Y. T. Yang, C. Callegari, X. L. Feng, K. L. Ekinci, and M. L. Roukes, "Zeptogram-scale nanomechanical mass sensing," Nano Letters, vol. 6, no. 4, pp. 583-586, 2006.

[139] C. Guthy, M. Belov, A. Janzen et al., "Large-scale arrays of nanomechanical sensors for biomolecular fingerprinting," Sensors and Actuators B, vol. 187, pp. 111-117, 2013.

[140] Y. K. Yoo, M.-S. Chae, J. Y. Kang, T. S. Kim, K. S. Hwang, and J. H. Lee, "Multifunctionalized cantilever systems for electronic nose applications," Analytical Chemistry, vol. 84, no. 19, pp. 8240-8245, 2012.

[141] J. Yinon, "Peer reviewed: detection of explosives by electronic noses," Analytical Chemistry, vol. 75, no. 1, pp. 98A-105A, 2003.

[142] H. P. Lang, M. K. Baller, R. Berger et al., "An artificial nose based on a micromechanical cantilever array," Analytica Chimica Acta, vol. 393, no. 1-3, pp. 59-65, 1999.

[143] J. Sarah Caygill, F. Davis, and S. P. J. Higson, "Current trends in explosive detection techniques," Talanta, vol. 88, pp. 14-29, 2012.

[144] G. Daqi and C. Wei, "Simultaneous estimation of odor classes and concentrations using an electronic nose with function approximation model ensembles," Sensors and Actuators B, vol. 120, no. 2, pp. 584-594, 2007.

[145] L. Zhang, F. Tian, C. Kadri, G. Pei, H. Li, and L. Pan, "Gases concentration estimation using heuristics and bio-inspired optimization models for experimental chemical electronic nose," Sensors and Actuators B, vol. 160, no. 1, pp. 760-770, 2011.

[146] D. Gao, F. Liu, and J. Wang, "Quantitative analysis of multiple kinds of volatile organic compounds using hierarchical models with an electronic nose," Sensors and Actuators B, vol. 161, no. 1, pp. 578-586, 2012.

[147] C. Distante, N. Ancona, and P. Siciliano, "Support vector machines for olfactory signals recognition," Sensors and Actuators B, vol. 88, no. 1, pp. 30-39, 2003.

[148] C. M. Bishop, Neural Networks for Pattern Recognition, Clarendon Press, Oxford, UK, 1995.

[149] J. S. Taylor and N. Cristianini, Kernel Methods for Pattern Analysis, Cambridge University Press, London, UK, 2004.

[150] N. Ramgir, N. Datta, M. Kaur et al., "Metal oxide nanowires for chemiresistive gas sensors: issues, challenges and prospects," Colloids and Surfaces A, 2013.

[151] H. Haick and D. Cahen, "Making contact: connecting molecules electrically to the macroscopic world," Progress in Surface Science, vol. 83, no. 4, pp. 217-261, 2008.

[152] D. R. Kim and X. Zheng, "Numerical characterization and optimization of the microfluidics for nanowire biosensors," Nano Letters, vol. 8, no. 10, pp. 3233-3237, 2008.

[153] P. X. Gao, Y. Ding, and Z. L. Wang, "Crystallographic orientation-aligned $\mathrm{ZnO}$ nanorods grown by a tin catalyst," Nano Letters, vol. 3, no. 9, pp. 1315-1320, 2003.

[154] J. B. Baxter and E. S. Aydil, "Epitaxial growth of $\mathrm{ZnO}$ nanowires on a- and c-plane sapphire," Journal of Crystal Growth, vol. 274, no. 3-4, pp. 407-411, 2005.

[155] D. Wang, R. Zhu, Z. Zhou, and X. Ye, "Controlled assembly of zinc oxide nanowires using dielectrophoresis," Applied Physics Letters, vol. 90, no. 10, Article ID 103110, 2007.

[156] C. S. Lao, J. Liu, P. Gao et al., " $\mathrm{ZnO}$ nanobelt/nanowire schottky diodes formed by dielectrophoresis alignment across au electrodes," Nano Letters, vol. 6, no. 2, pp. 263-266, 2006.

[157] J. Suehiro, N. Nakagawa, S.-I. Hidaka et al., "Dielectrophoretic fabrication and characterization of a $\mathrm{ZnO}$ nanowire-based UV photosensor," Nanotechnology, vol. 17, no. 10, pp. 2567-2573, 2006.

[158] D. Zhang, S. Wang, K. Cheng et al., "Controllable fabrication of patterned $\mathrm{ZnO}$ nanorod arrays: investigations into the impacts on their morphology," ACS Applied Materials \& Interfaces, vol. 4, no. 6, pp. 2969-2977, 2012.

[159] J.-W. Liu, H.-W. Liang, and S.-H. Yu, "Macroscopic-scale assembled nanowire thin films and their functionalities," Chemical Reviews, vol. 112, no. 8, pp. 4770-4799, 2012.

[160] O. Assad, A. M. Leshansky, B. Wang, T. Stelzner, S. Christiansen, and H. Haick, "Spray-coating route for highly aligned and largescale arrays of nanowires," ACS Nano, vol. 6, no. 6, pp. 47024712, 2012.

[161] D. Tsivion, M. Schvartzman, R. Popovitz-Biro, and E. Joselevich, "Guided growth of horizontal $\mathrm{ZnO}$ nanowires with controlled orientations on flat and faceted sapphire surfaces," ACS Nano, vol. 6, pp. 6433-6445, 2012.

[162] X. Liu, Y.-Z. Long, L. Liao, X. Duan, and Z. Fan, "Large-scale integration of semiconductor nanowires for high-performance flexible electronics," ACS Nano, vol. 6, no. 3, pp. 1888-1900, 2012.

[163] C. Kallesøe, C.-Y. Wen, T. J. Booth et al., "In situ tem creation and electrical characterization of nanowire devices," Nano Letters, vol. 12, no. 6, pp. 2965-2970, 2012.

[164] A. Pevzner, Y. Engel, R. Elnathan, A. Tsukernik, Z. Barkay, and F. Patolsky, "Confinement-guided shaping of semiconductor nanowires and nanoribbons: 'writing with nanowires," Nano Letters, vol. 12, no. 1, pp. 7-12, 2012.

[165] S.-Y. Min, T.-S. Kim, B. J. Kim et al., "Large-scale organic nanowire lithography and electronics," Nature Communications, vol. 4, article 1773, 2013. 
[166] M. Heurlin, M. H. Magnusson, D. Lindgren et al., "Continuous gas-phase synthesis of nanowires with tunable properties," Nature, vol. 492, pp. 90-94, 2012.

[167] Z. Fan, J. C. Ho, T. Takahashi et al., "Toward the development of printable nanowire electronics and sensors," Advanced Materials, vol. 21, no. 37, pp. 3730-3743, 2009.

[168] C. Bambang Dwi Kuncoro, Armansyah, N. H. Saad, A. Jaffar, C. Y. Low, and S. Kasolang, "Wireless e-nose sensor node: state of the art," Procedia Engineering, vol. 41, pp. 1405-1411, 2012.

[169] Z. L. Wang and J. Song, "Piezoelectric nanogenerators based on zinc oxide nanowire arrays," Science, vol. 312, no. 5771, pp. 243246, 2006.

[170] S. J. Park, O. S. Kwon, S. H. Lee, H. S. Song, T. H. Park, and J. Jang, "Ultrasensitive flexible graphene based field-effect transistor (FET)-type bioelectronic nose," Nano Letters, vol. 12, pp. 5082-5090, 2012.

[171] S. S. Chou, M. De, J. Luo, V. M. Rotello, J. Huang, and V. P. Dravid, "Nanoscale graphene oxide (nGO) as artificial receptors: implications for biomolecular interactions and sensing," Journal of the American Chemical Society, vol. 134, no. 40, pp. 16725-16733, 2012.

[172] T. Kinkeldei, C. Zysset, K. H. Cherenack, and G. Troster, "A textile integrated sensor system for monitoring humidity and temperature," in Proceedings of the 16th International Solid-State Sensors, Actuators and Microsystems Conference (TRANSDUCERS '11), pp. 1156-1159, June 2011.

[173] T. Kinkeldei, C. Zysset, N. Münzenrieder, and G. Tröster, "An electronic nose on flexible substrates integrated into a smart textile," Sensors and Actuators B, vol. 174, pp. 81-86, 2012.

[174] J.-W. Han, B. Kim, J. Li, and M. Meyyappan, "A carbon nanotube based ammonia sensor on cotton textile," Applied Physics Letters, vol. 102, Article ID 193104, 4 pages, 2013.

[175] S. Park and S. Jayaraman, "Smart textile-based wearable biomedical systems: a transition plan for research to reality," IEEE Transactions on Information Technology in Biomedicine, vol. 14, no. 1, pp. 86-92, 2010.

[176] S. H. Lee, O. S. Kwon, H. S. Song et al., "Mimicking the human smell sensing mechanism with an artificial nose platform," Biomaterials, vol. 33, no. 6, pp. 1722-1729, 2012.

[177] W. Yoon, S. H. Lee, O. S. Kwon et al., "Polypyrrole nanotubes conjugated with human olfactory receptors: high-performance transducers for FET-Type bioelectronic noses," Angewandte Chemie-International Edition, vol. 48, no. 15, pp. 2755-2758, 2009.

[178] G. Sberveglieri, I. Concina, E. Comini, M. Falasconi, M. Ferroni, and V. Sberveglieri, "Synthesis and integration of tin oxide nanowires into an electronic nose," Vacuum, vol. 86, no. 5, pp. 532-535, 2012.

[179] V. V. Sysoev, B. K. Button, K. Wepsiec, S. Dmitriev, and A. Kolmakov, "Toward the nanoscopic "electronic nose": hydrogen vs carbon monoxide discrimination with an array of individual metal oxide nano- and mesowire sensors," Nano Letters, vol. 6, no. 8, pp. 1584-1588, 2006.

[180] B. R. Goldsmith, J. J. Mitala Jr., J. Josue et al., "Biomimetic chemical sensors using nanoelectronic readout of olfactory receptor proteins," ACS Nano, vol. 5, no. 7, pp. 5408-5416, 2011.

[181] S. H. Lee, H. J. Jin, H. S. Song, S. Hong, and T. H. Park, "Bioelectronic nose with high sensitivity and selectivity using chemically functionalized carbon nanotube combined with human olfactory receptor," Journal of Biotechnology, vol. 157, no. 4, pp. 467-472, 2012.
[182] Q. Zhang, C. Xie, S. Zhang et al., "Identification and pattern recognition analysis of Chinese liquors by doped nano $\mathrm{ZnO}$ gas sensor array," Sensors and Actuators B, vol. 110, no. 2, pp. 370376, 2005.

[183] J. Gong, Q. Chen, W. Fei, and S. Seal, "Micromachined nanocrystalline $\mathrm{SnO}_{2}$ chemical gas sensors for electronic nose," Sensors and Actuators B, vol. 102, no. 1, pp. 117-125, 2004.

[184] A. W. Snow, H. Wohltjen, and N. L. Jarvis, "MIME chemical vapor microsensors," in NRL Review, J. D. Bultman, Ed., pp. 4555, Naval Research Laboratory, Washington, DC, USA, 2002.

[185] E. Chevallier, E. Scorsone, and P. Bergonzo, "Modified diamond nanoparticles as sensitive coatings for chemical SAW sensors," Procedia Chemistry, vol. 1, no. 1, pp. 943-946, 2009.

[186] U. Tisch and H. Haick, "Arrays of nanomaterial-based sensors for breath testing," in Volatile Biomarkers: Non-Invasive Diagnosis in Physiology and Medicine, chapter 16, pp. 301-323, Elsevier, Amsterdam, The Netherlands, 2013.

[187] Y. Engel, R. Elnathan, A. Pevzner, G. Davidi, E. Flaxer, and F. Patolsky, "Supersensitive detection of explosives by silicon nanowire arrays," Angewandte Chemie-International Edition, vol. 49, no. 38, pp. 6830-6835, 2010.

[188] C. Wongchoosuk, A. Wisitsoraat, A. Tuantranont, and T. Kerdcharoen, "Portable electronic nose based on carbon nanotube$\mathrm{SnO}_{2}$ gas sensors and its application for detection of methanol contamination in whiskeys," Sensors and Actuators B, vol. 147, no. 2, pp. 392-399, 2010.

[189] B. Kumar, J.-F. Feller, M. Castro, and J. Lu, "Conductive bioPolymer nano-Composites (CPC): chitosan-carbon nanotube transducers assembled via spray layer-by-layer for volatile organic compound sensing," Talanta, vol. 81, no. 3, pp. 908-915, 2010.

[190] S. Dragonieri, J. T. Annema, R. Schot et al., "An electronic nose in the discrimination of patients with non-small cell lung cancer and COPD," Lung Cancer, vol. 64, no. 2, pp. 166-170, 2009. 

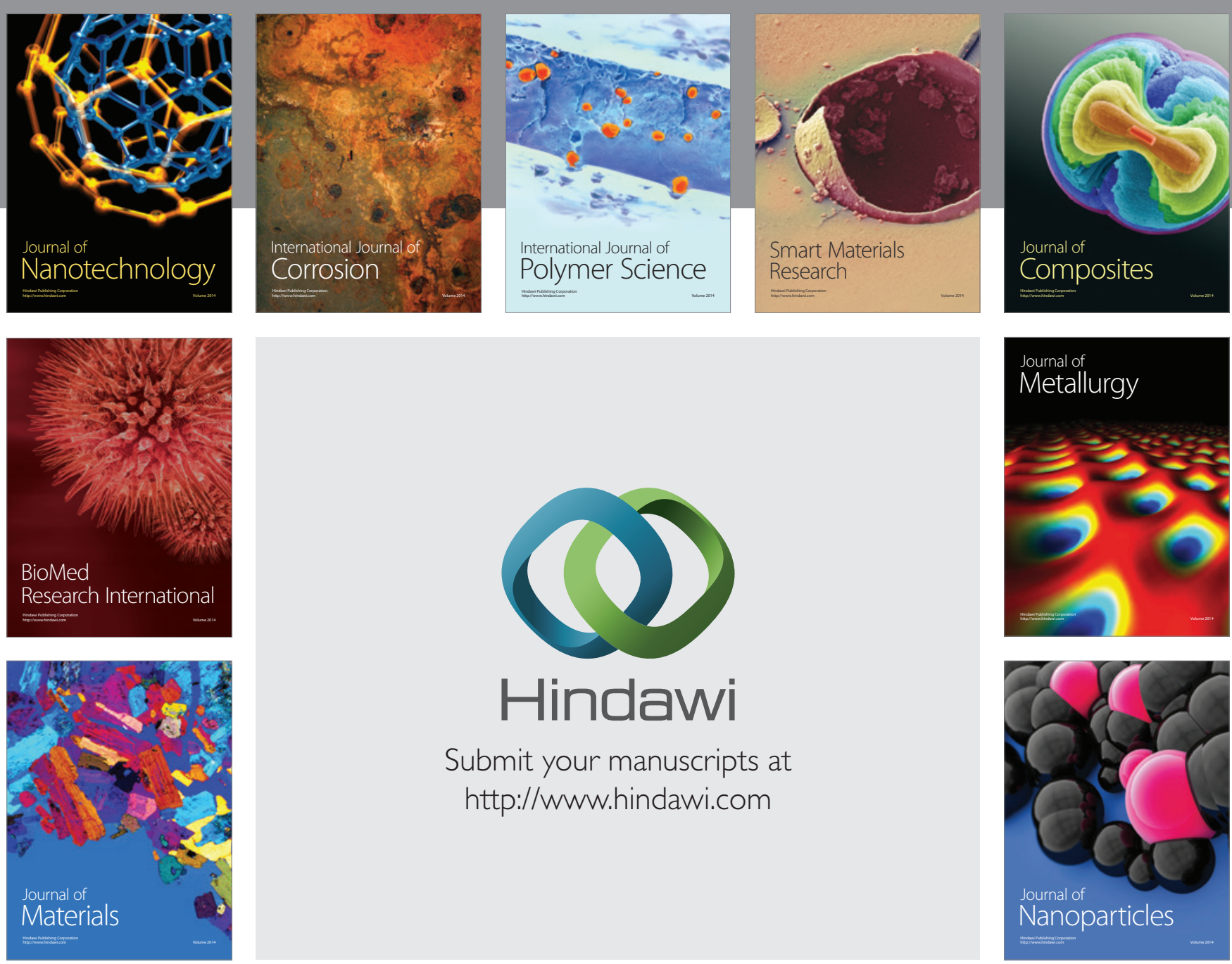

Submit your manuscripts at http://www.hindawi.com
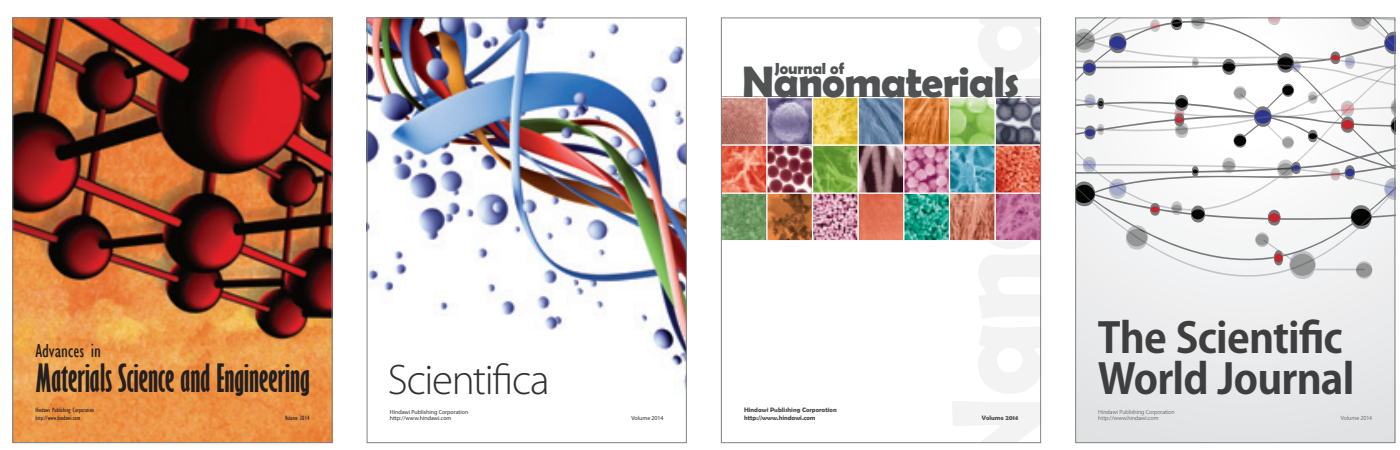

\section{The Scientific World Journal}
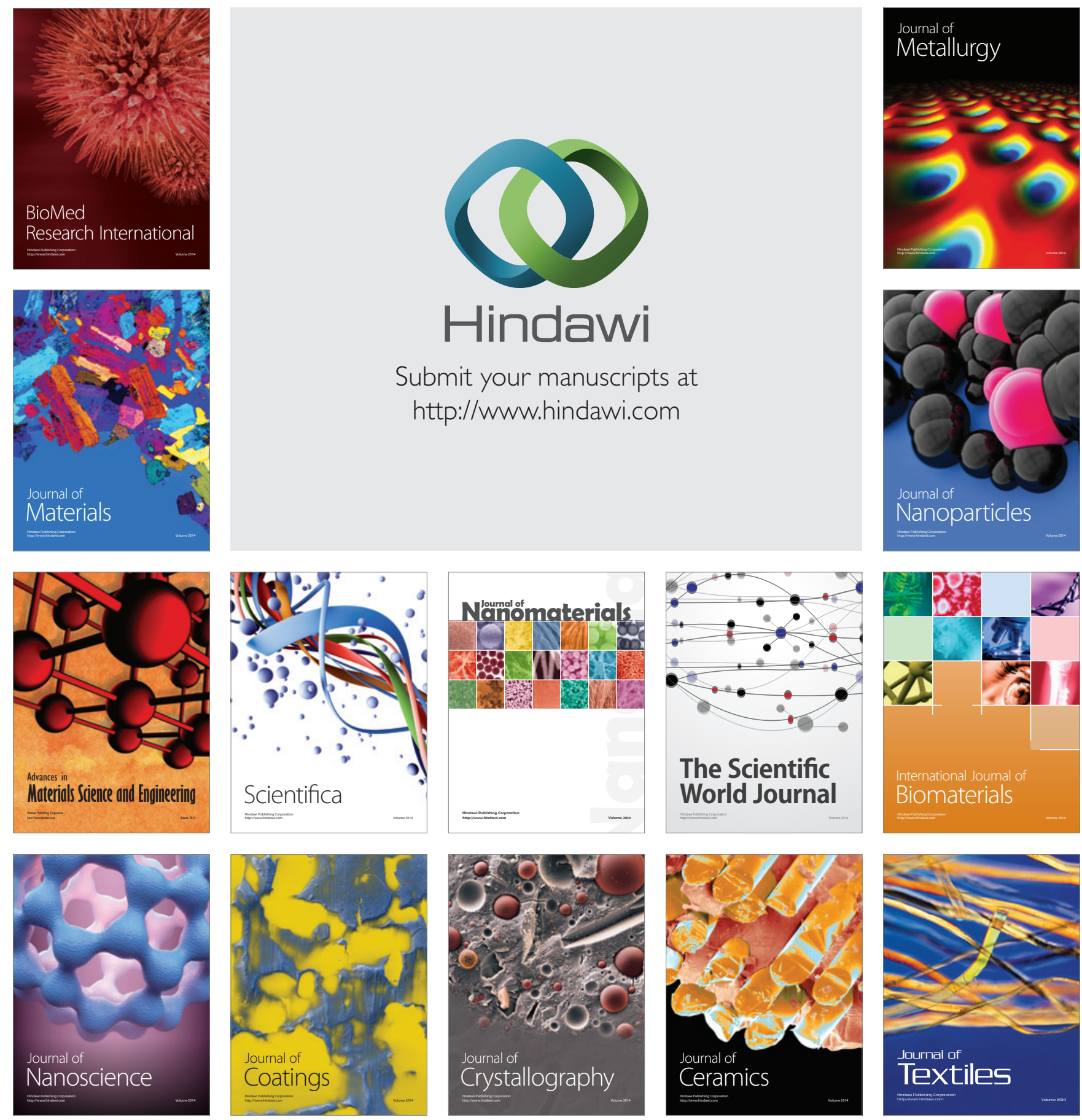